DOI: $10.1002 /$ ((please add manuscript number))

Article type: Full Paper

\title{
Multi-responsive "turn-on" nanocarriers for efficient site-specific gene delivery in vitro and in vivo
}

Yiyan He ${ }^{1}$, Jie Zhou ${ }^{1}$, Shengnan $\mathrm{Ma}^{1}$, Yu Nie ${ }^{1}$, Dong Yue ${ }^{1}$, Qian Jiang ${ }^{1}$, Aisha Roshan Mohamed Wali ${ }^{3}$, James Zhenggui Tang ${ }^{3}$, Zhongwei $\mathrm{Gu}^{12 *}$

${ }^{1}$ National Engineering Research Center for Biomaterials, Sichuan University, 29 Wangjiang Road, Chengdu 610064, P. R. China.*E-mail: zwgu@scu.edu.cn \& zwgu1006@,hotmail.com (Prof. Zhongwei Gu); Fax: +86-28-85410653.

${ }^{2}$ College of Materials Science and Engineering, Nanjing Tech University, 30 South Puzhu Road, Nanjing 211816, P. R. China

${ }^{3}$ Faculty of Science and Engineering, School of Pharmacy, University of Wolverhampton, Wulfruna Street, Wolverhampton WV1 1SB, UK

Keywords: gene delivery, nanocarriers, multi-responsive, site-specific, biological barriers

Systemic gene delivery is a complicated and multistep process that confronts numerous biological barriers. It remains a formidable challenge to exploit a single gene carrier with multiple features to combat all obstacles collectively. Herein, we demonstrate a multiresponsive "turn-on" polyelectrolyte complex (DNA/OEI-SS ${ }_{\mathrm{x}} / \mathrm{HA}-\mathrm{SS}-\mathrm{COOH}$, DSS) delivery system with a sequential self-assembly of disulfide-conjugated oligoethylenimine $\left(\mathrm{OEI}-\mathrm{SS}_{\mathrm{x}}\right)$ and disulfide bond-modified hyaluronic acid envelope (HA-SS-COOH) that can combat multiple biological barriers collectively when administered intravenously. DSS is designed to effectively accumulate at the tumor tissue and to be internalized into tumor cells by recognizing CD44. The multi-responsive "turn-on" DSS can respond to the alterations of hyaluronidases and glutathione at both the tumor site and at the intracellular milieu. Sequential degradation and detachment of the HA-SS-COOH envelope followed by the dissociation of the OEI-SSx/DNA inner core contributes to the activation of the endosomal escape and gene release functions, thus greatly enhancing nuclear gene delivery. A systematic investigation of DSS has revealed that the tumor accumulation ability, internalization and 
endosome escape of the DSS nanocarriers, DNA unpacking and nuclear transportation are all remarkably improved by the multi-responsive "turn-on" design resulting in highly efficient gene transfection in vitro and in vivo.

\section{Introduction}

The imperative issue to achieve satisfactory cancer gene therapy ultimately lies in the ability of carriers to deliver exogenous therapeutic genes to target cells. ${ }^{[1]}$ Because systemic gene delivery is a complicated and multistep process, gene carriers have to overcome numerous biological barriers $^{[2]}$ that hinder the effective delivery of DNA to target locations, including (i) gene condensation while avoiding polyanion-mediated dissociation and DNase degradation during blood circulation, (ii) extravasation through the leaky tumor vasculature (passive targeting) and accumulation in the interstitial space where carriers are retained due to the lack of lymphatic clearance (enhanced permeability and retention effect) ${ }^{[3]}$, (iii) internalization into target cells to reduce toxic side-effects, (iv) endosomal escape, (v) dissociation of gene carriers and unpacking of the DNA, and (vi) delivery into the nucleus for transfection. Although great efforts have been devoted to develop various gene carriers for overcoming one or several biological barriers, it remains a formidable challenge to exploit a single multifunctional gene carrier to combat the majority of obstacles simultaneously to fulfill satisfactory gene transfection efficiency with minimal toxicity. ${ }^{[4]}$

It is encouraging to note that a multitude of cationic lipids and polymers, ${ }^{[5]}$ such as polyethylenimine (PEI), polyamidoamine (PAMAM) and polylysine (PLL), have been extensively tailored to fight against hurdles in the gene delivery process. One of the highly promising strategies is to design stimulus-responsive nanocarriers for overcoming the stability dilemma and reducing toxicity. Redox-sensitive degradable polycations ${ }^{[6]}$ allow both condensation and delivery of nucleic acids. This type of polycation is designed to remain stable under physiological conditions, whereas dissociation takes place rapidly and selectively 
upon intracellular delivery. This design also has been demonstrated to reduce toxicity while retaining the gene transfer ability. Actually, most polycation-based nanocarriers can selfassemble from electrostatic interactions between cationic polymers and anionic nucleic acids and feature a positively charged surface and can bind to a cell membrane having a negative charge to achieve pinocytosis or endocytosis. This type of pinocytosis or endocytosis is always considered to be non-specific adsorption regardless of the cell type ${ }^{[7]}$ and generally leads to non-specificity in biodistribution and safety problems.

Varieties in comprehensive design criteria have recently been used to overcome the abovementioned limitations of polycation-based nanocarriers. ${ }^{[5,8]}$ One attractive strategy proposes the use of a shelter with functional groups that can connect to the preformed inner cationic core. The most common shielding agents are hydrophilic macromolecules - PEG, ${ }^{[8 a, 8 c, 9]}$ polysaccharides, ${ }^{[10]}$ polyaspartamide and polyglutamic acid derivatives. ${ }^{[8 \mathrm{~b}, 8 \mathrm{cc}, 11]}$ Polymer-lipid hybrid systems ${ }^{[12]}$ (also known as MEND ${ }^{[13]}$ and $\operatorname{LPD}^{[14]}$ ) are also advanced approaches. On the one hand, these approaches can alter the surface properties of polycation-based nanocarriers by shielding their positive surface charges. This approach would be beneficial in eliminating non-specific interactions with anionic serum proteins and avoiding nanocarrier dissociations due to competitive binding of heparin during blood circulation. However, conversely, shielding the polycation-based nanocarriers with neutral or anionic polymers reduces the internalization efficiency and the endosomal escape ability.

Therefore, it is urgent to develop a gene delivery system with numerous characteristics integrated and optimized to fight against multiple impediments simultaneously during gene delivery. Herein, taking the transfection barriers involved in non-viral gene delivery into account, we demonstrate multi-responsive "turn-on" polyelectrolyte complex (DNA/OEI$\mathrm{SS}_{\mathrm{x}} / \mathrm{HA}-\mathrm{SS}-\mathrm{COOH}, \mathrm{DSS}$ ) as multifunctional gene carriers with sequential self-assembly of 
disulfide-conjugated oligoethylenimine $\left(\mathrm{OEI}-\mathrm{SS}_{\mathrm{x}}\right)$ and disulfide bond-modified hyaluronic acid envelopes (HA-SS-COOH) (Scheme 1). CD44 is a major cell surface receptor for HA and is overexpressed in various tumors. The N-terminal link module homology domain of CD44 is responsible for binding to HA. ${ }^{[15]}$ Because HA has a high affinity for the cancer marker CD44, HA-SS-COOH is utilized not only as a targeting moiety but also for a detachable envelope to DNA/OEI-SSx inner polyplexes via electrostatic forces. DSS are designed to effectively accumulate and become internalized in tumors, which overexpress the CD44 receptor, and then to activate endosomal escape and gene release functions resulting in highly efficient site-specific gene transfection in vitro and in vivo. The multi-responsive "turnon" DSS nanocarriers can sense the tumor biological milieu and respond to the alterations in hyaluronidases or glutathione (GSH) at both the tumor site and the intracellular milieu. The HA-SS-COOH envelope is prone to degradation by hyaluronidases. The levels of hyaluronidases are always high in several types of carcinomas including liver cancer, ${ }^{[16]}$ colorectal carcinoma $^{[17]}$ and breast cancer ${ }^{[18]}$. Hyaluronidases appear not only on the exofacial surface but also inside cells. Accordingly, internalization of DSS is a crucial step for envelope degradation. After binding to the CD44 receptor, hyaluronidase-2 outside cells with a broader $\mathrm{pH}^{[19]}$ optimum initiates extracellular degradation of HA-SS-COOH into fragments of $\sim 20$ $\mathrm{kDa}$. After forming caveolae, transferring to endosomes and finally fusing with lysosomes, the envelope fragments are further degraded into oligosaccharides by hyaluronidase- 1 inside cells $^{[20]}$. Furthermore, the disulfide bonds in the HA-SS-COOH envelope and OEI-SSx/DNA inner core readily cleave due to the high concentration of GSH $(1-10 \mathrm{mM})^{[21]}$ in the cytosol leading to the dissociation of the nanocarriers, activation of endosomal escape and the release of DNA on-demand. In this study, DSS nanocarriers were systematically investigated in comparison with control nanocarriers (insensitive golden standard DNA/PEI (DP), nonenveloping DNA/OEI-SSx (DS) and stable envelope DNA/OEI-SSx/HA (DSH)). The tumor accumulation ability, internalization and endosome escape of the DSS nanocarriers, DNA 
unpacking and nuclear transportation were all remarkably improved by the multi-responsive "turn-on" design resulting in enormously efficient gene transfection in vitro and in vivo.

$\begin{array}{ll}\begin{array}{l}\text { Acronyms } \\ \text { OEI-SS }\end{array} & \\ \text { HA-SS-COOH } & \text { Disulfide cross-linked branch OEI } 800 \\ & \text { HA with } 30 \text { mol } \% \text { disulfide modification between pendent carboxyl groups and } \\ \text { backbone } \\ \text { DS } & \text { DNA/OEI-SS } \text { p }_{\mathrm{x}} \text { polyplexes } \\ \text { DSH } & \text { DNA/OEI-SS } / \text { HA polyplexes } \\ \text { DSS } & \text { DNA/OEI-SS } / \text { HA-SS-COOH polyplexes } \\ \text { DP } & \text { DNA/PEI polyplexes } \\ \text { DPH } & \text { DNA/PEI/HA polyplexes } \\ \text { DPS } & \text { DNA/PEI/HA-SS-COOH polyplexes }\end{array}$

\section{Results}

\subsection{Design, Synthesis and Characterization of the Nanocarriers}

The multi-responsive "turn-on" DNA/OEI-SSx/HA-SS-COOH (DSS) nanocarriers were synthesized (Figure S1, Supporting Information) consisting of a bioreducible DNA/OEI-SSx polyplex core and a hyaluronidase and GSH dual-sensitive HA-SS-COOH envelope. Its reductive degradation behavior was confirmed using GPC analysis. The molecular weight distribution of the OEI-SSx is narrow and comparable to PEI $25 \mathrm{kDa}$ before treatment but degraded significantly after incubation with $10 \mathrm{mM}$ dithiothreitol (DTT) for half an hour with a characteristic molecular weight close to OEI $800 \mathrm{Da}$ (Figure S2A, Supporting Information). The molecular structure of the HA-SS-COOH envelope with $30 \mathrm{~mol} \%$ disulfide linkages was also confirmed by ${ }^{1}$ HNMR spectra (Figure S2B, Supporting Information). DNA was complexed with OEI-SSx in HBG buffer resulting in DNA/OEI-SSx polyplexes. A detachable and targeted outer HA-SS-COOH envelope was then added onto the polyplexes surface to generate DNA/OEI-SSx/HA-SS-COOH nanocarriers in a core-shell structure (Scheme 1). The HA-SS-COOH envelope is expected to degrade stepwise by hyaluronidases at both the tumor site and in the intracellular milieu and further respond to high concentration GSH by completely detaching the envelope and disassembling the DNA-encapsulating core. These multi-responsive features would be beneficial for facilitating endosomal escape and ondemand unpacking of the loaded genes for nuclear delivery. 

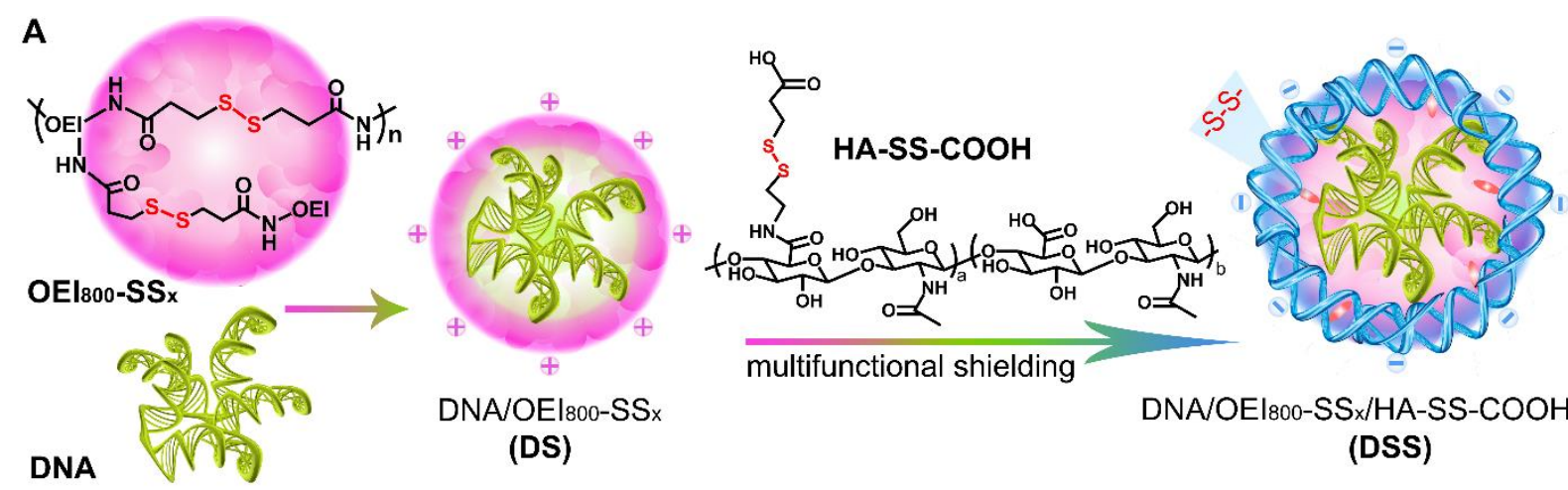

DNA/OEl800-SS $/ \mathrm{HA}-\mathrm{SS}-\mathrm{COOH}$

(DSS)

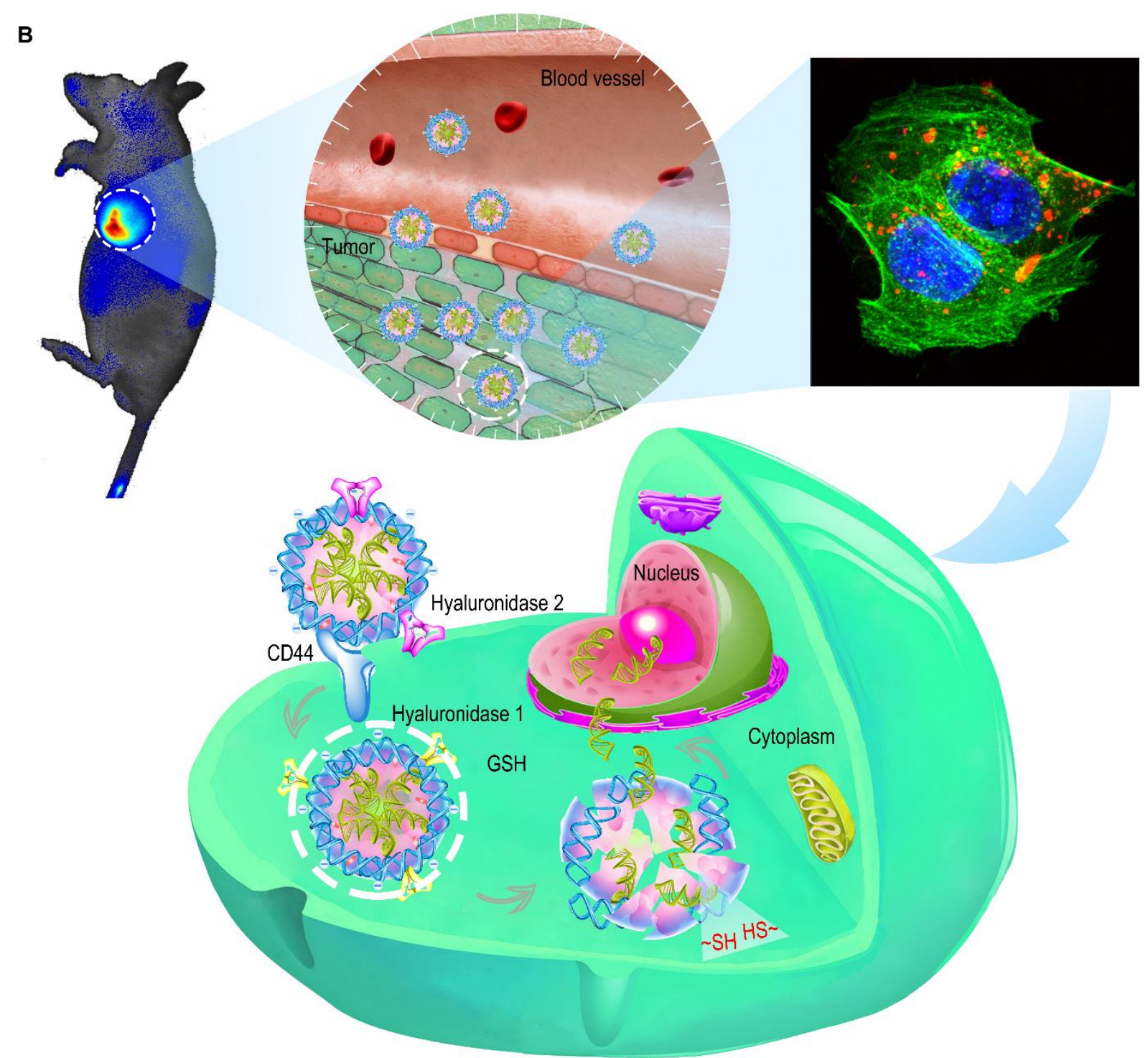

Scheme 1. (A) Schematic fabrication process of the multi-responsive "turn-on" DSS nanocarriers. (B) Schematic representation of DSS-mediated gene delivery.

The size and zeta potential variation of DSS under reductive conditions (10 mM DTT) were measured (Figure $1 \mathrm{~A}$ and B). The particle sizes of the DSS $\left(\mathrm{OEI}_{-} \mathrm{SS}_{\mathrm{x}} / \mathrm{DNA}=10 ; \mathrm{w} / \mathrm{w}\right)$ ranged from 110 to $196 \mathrm{~nm}$, and the zeta potential was from $+27.0 \mathrm{mV}$ to $+5.8 \mathrm{mV}$ depending 
on the HA-SS-COOH/DNA and OEI-SSx/DNA ratios. When treated with $10 \mathrm{mM}$ DTT, the size of DSS sharply increased to approximately 1 micron and the zeta potential decreased, indicating the aggregation of DSS nanocarriers. The particle sizes of the DSS $\left(\mathrm{OEI}_{-} \mathrm{SS}_{\mathrm{x}} / \mathrm{DNA}\right.$ $=10, \mathrm{HA}-\mathrm{SS}-\mathrm{COOH} / \mathrm{DNA}=2 ; \mathrm{w} / \mathrm{w})$ dispersed in acetate buffer without hyaluronidases presented no significant changes during the measurement process, suggesting a high level of stability. When incubated with hyaluronidase at concentrations of 60 and 120 units $\mathrm{mL}^{-1}$ for $80 \mathrm{~min}$, however, the size sharply increased to $712.8 \pm 45.6 \mathrm{~nm}$ and $868.1 \pm 52.4 \mathrm{~nm}$, implying the degradation of the HA-SS-COOH envelope (Figure 1C). TEM images showed that DSH $\left(\mathrm{OEI}_{-S S_{\mathrm{x}}} / \mathrm{DNA}=10, \mathrm{HA} / \mathrm{DNA}=1 ; \mathrm{w} / \mathrm{w}\right)$ and DSS $\left(\mathrm{OEI}-\mathrm{SS} \mathrm{x}_{\mathrm{x}} / \mathrm{DNA}=10, \mathrm{HA}-\mathrm{SS}-\right.$ $\mathrm{COOH} / \mathrm{DNA}=2 ; \mathrm{w} / \mathrm{w}$ ) had a similar uniform spherical morphology of approximately $120 \mathrm{~nm}$ (Figure 1D). When treated with 120 units $\mathrm{mL}^{-1}$ hyaluronidase for $30 \mathrm{~min}$, the morphology of DSS became irregular, but the size did not increase significantly in comparison with DLS measurement. The discrepancy between TEM and DLS is partly because DLS measures a hydrodynamic size rather than a physical size, and DLS is biased towards larger size fractions. When further treated with $10 \mathrm{mM}$ DTT, as expected, DSS exhibited an irregular and aggregated morphology.

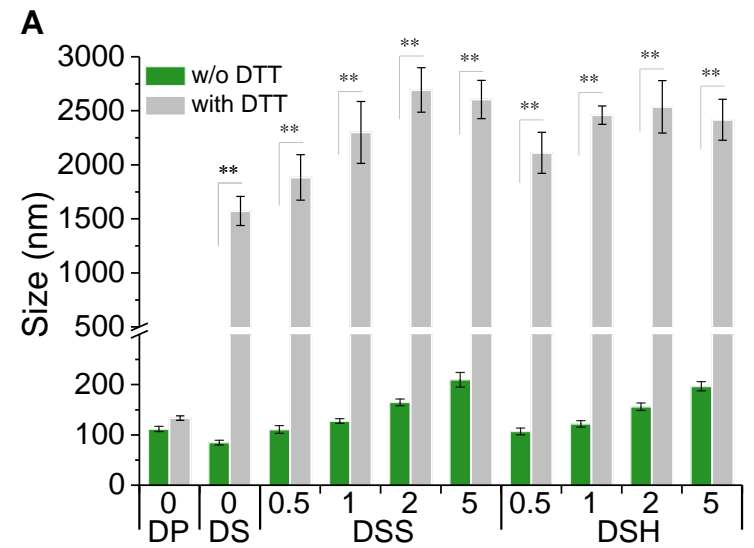

Envelope/DNA ratio (w/w)

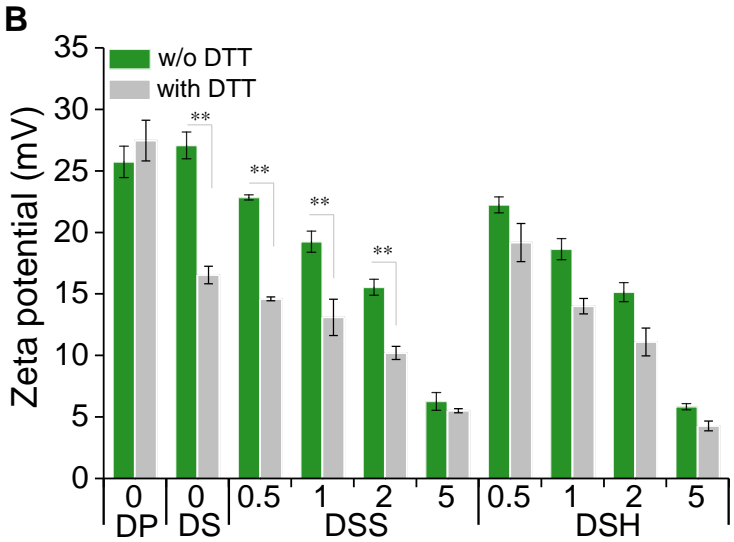

Envelope/DNA ratio (w/w) 

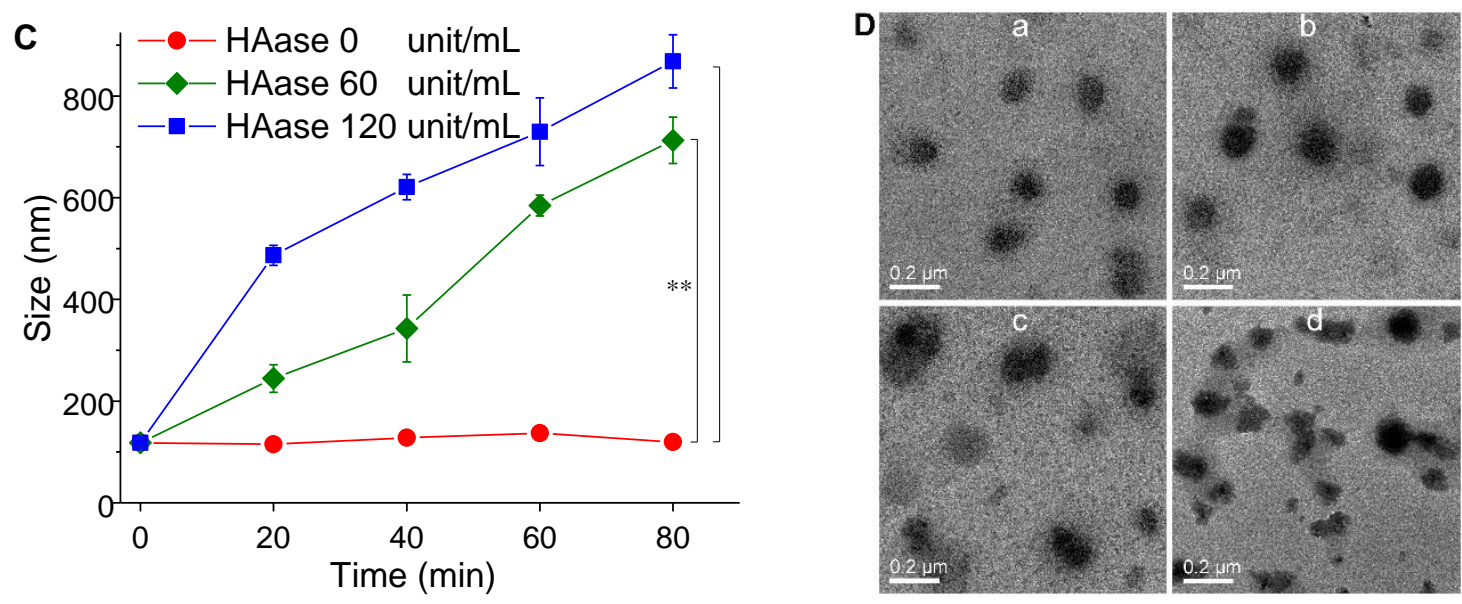

Figure 1. (A) Particle sizes and (B) zeta potential of the indicated gene carriers (DS, DSH and DSS were prepared at OEI-SS $\mathrm{x}_{\mathrm{x}}$ to DNA weight ratio of 10) in the absence or presence of 10 mM DTT. (C) Varies in size of DSS $\left(\mathrm{OEI}-\mathrm{SS}_{\mathrm{x}} / \mathrm{DNA}=10, \mathrm{HA}-\mathrm{SS}-\mathrm{COOH} / \mathrm{DNA}=2 ; \mathrm{w} / \mathrm{w}\right)$ incubated with different concentrations of hyaluronidase for different times. $\left(\mathrm{n}=6,{ }^{*} * p<0.05\right.$ by one-way ANOVA, followed by Tukey's post-hoc test). (D) TEM images of (a) DSH (OEI$\mathrm{SS}_{\mathrm{x}} / \mathrm{DNA}=10, \mathrm{HA} / \mathrm{DNA}=1$; w/w $)$, (b) DSS $\left(\mathrm{OEI}-\mathrm{SS}_{\mathrm{x}} / \mathrm{DNA}=10, \mathrm{HA}-\mathrm{SS}-\mathrm{COOH} / \mathrm{DNA}=2\right.$; w/w), (c) DSS treated with 120 units $/ \mathrm{mL}$ hyaluronidase, and (d) DSS treated with hyaluronidase (120 units/mL) and DTT (10 mM).
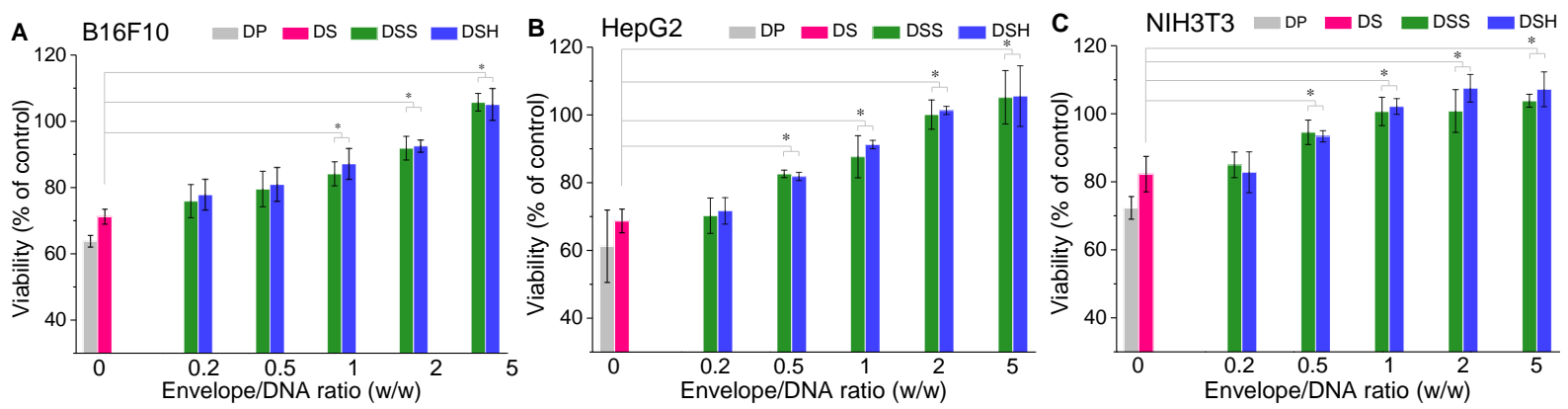

Figure 2. Cell viability assays of various gene carriers with different envelope/DNA ratios in (A) B16F10, (B) HepG2 and (C) NIH3T3 cells for $24 \mathrm{~h}$ of incubation ( $\mathrm{n}=6,{ }^{*} p<0.05$ by two-way ANOVA, followed by Tukey's post-hoc test). (DNA concentration is $2 \mu \mathrm{g} / \mathrm{mL}$. DP: PEI/DNA $=1.33$; DS: OEI-SS $/$ /DNA = 10; DSS: OEI-SS $/$ DNA = 10, HA-SS-COOH/DNA = $0.2 \sim 5$; DSH: OEI-SS $\left._{\mathrm{x}} / \mathrm{DNA}=10, \mathrm{HA} / \mathrm{DNA}=0.2 \sim 5 ; \mathrm{w} / \mathrm{w}\right)$

\subsection{Cytotoxicity Assessment}

Concentration-dependent cytotoxicity of $\mathrm{PEI}_{25 \mathrm{kDa}}$, OEI800Da and OEI-SSx was investigated in

HepG2 cells. As shown in Figure S3, less cytotoxicity was found for OEI-SSx compared with

PEI at the same concentration. To further evaluate the anionic coating effect of HA-SS-

$\mathrm{COOH}$ on OEI-SSx/DNA polyplexes, the cytotoxicity of the various gene carriers at working concentrations was assessed in B16F10, HepG2 and NIH3T3 cells. The cell viability of DPtreated B16F10, HepG2 and NIH3T3 cells was less than 80\% (Figure 2). Compared with DP, 
DS showed slightly greater viability. The non-degradable PEI is known to induce significant cytotoxic side effects. The strategy of preparing high-molecular-weight polycations from lowmolecular-weight oligocations via biodegradable disulfide linkages is beneficial in reducing toxicity. After inclusion of the HA and HA-SS-COOH envelope, an increase in the ratio of envelope to DNA significantly increased the viability of B16F10, HepG2 and NIH3T3 cells to the level of blank cells. The high viability (> 80\%) indicates that DSS and DSH did not have significant toxicity at the working concentrations.
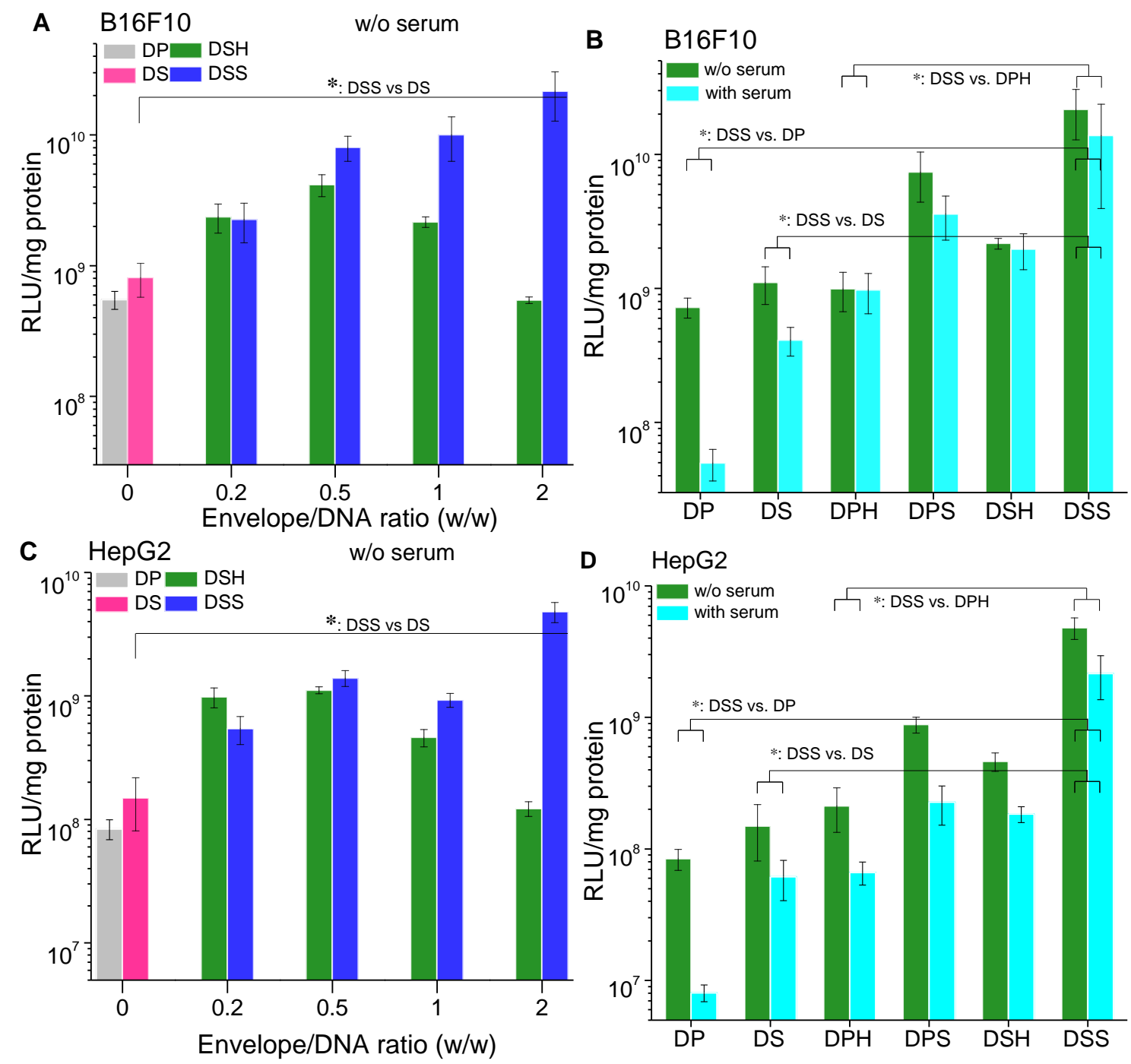

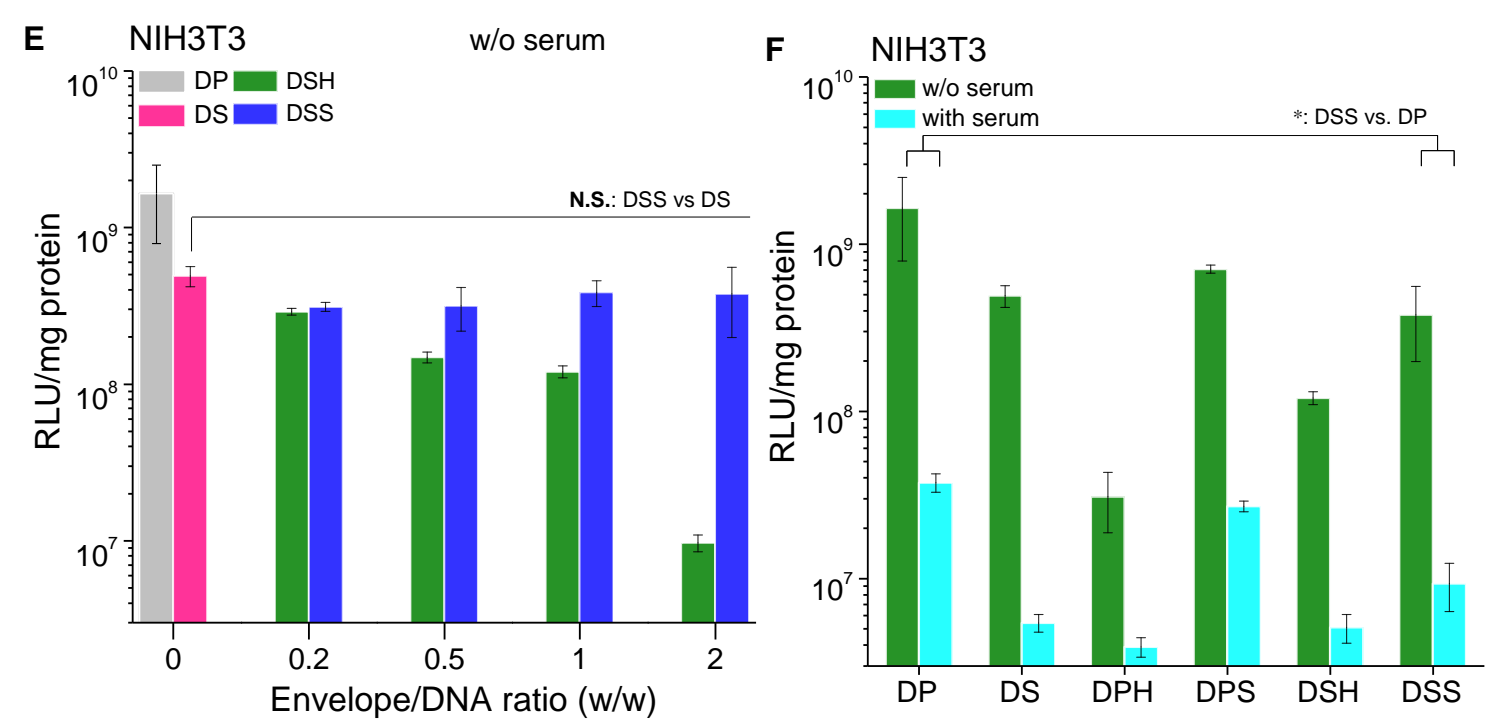

Figure 3. In vitro luciferase expression of different gene carriers in B16F10 (A, B), HepG2 $(\mathrm{C}, \mathrm{D})$ and NIH3T3 (E, F) cells. ( $\mathrm{n}=6,{ }^{*} p<0.05$ by two-way ANOVA, followed by Tukey's post-hoc test). (DNA concentration is $2 \mu \mathrm{g} / \mathrm{mL}$. For Fig. $3 \mathrm{~A}, \mathrm{C}$, and E, DP: PEI/DNA = 1.33; DS: OEI-SSx/DNA $=10$; DSH: OEI-SSx/DNA $=10$, HA/DNA $=0.2 \sim 2$; DSS: OEI$\mathrm{SSx} / \mathrm{DNA}=10$, HA-SS-COOH/DNA = $0.2 \sim 2$; w/w. For Fig. $3 \mathrm{~B}, \mathrm{D}$, and F, DPH: PEI/DNA $=1.33, \mathrm{HA} / \mathrm{DNA}=1$; DPS: PEI/DNA $=1.33, \mathrm{HA}-\mathrm{SS}-\mathrm{COOH} / \mathrm{DNA}=1 ;$ DSH: OEISSx/DNA $=10, \mathrm{HA} / \mathrm{DNA}=1$; DSS: OEI-SSx/DNA = 10, HA-SS-COOH/DNA = 2; w/w.)

\subsection{In Vitro Transfection}

The superiority with respect to gene transfection of the multi-responsive "turn-on" DSS was evaluated in NIH3T3 (CD44 negative ${ }^{[22]}$ ), HepG2 (CD44 positive ${ }^{[23]}$ ) and B16F10 (CD44 positive $^{[24]}$ ) cells (Figure 3). The gene expression level of the DS was much stronger than that offered by DP in both B16F10 and HepG2 cells. Different weight ratios of the HA-SS-COOH envelope to DNA in the range from 0.2 to 2 have successfully improved the transfection efficiency. In serum-free medium and $10 \%$ serum conditions, among them, DSS (the weight ratios of OEI-SS $\mathrm{x}_{\mathrm{x}}$ and HA-SS-COOH to DNA were 10 and 2, respectively) was the best with approximately 57-fold and 267-fold greater transfer rates than the DP group in HepG2 cells, respectively (Figure $3 \mathrm{C}$ and $\mathrm{D}, p<0.05$ ). Compared to the stable $\mathrm{DSH}$ envelope, which has the same OEI-SS $\mathrm{X}_{\mathrm{X}} \mathrm{DNA}$ polyplexes core, multi-responsive "turn-on" DSS nanocarriers showed significantly greater luciferase levels $(p<0.05)$. Similar results can be yielded from the B16F10 cell line (Figure 3A and B) but not in HA receptor-negative NIH3T3 cells (Figure 3E and F). 


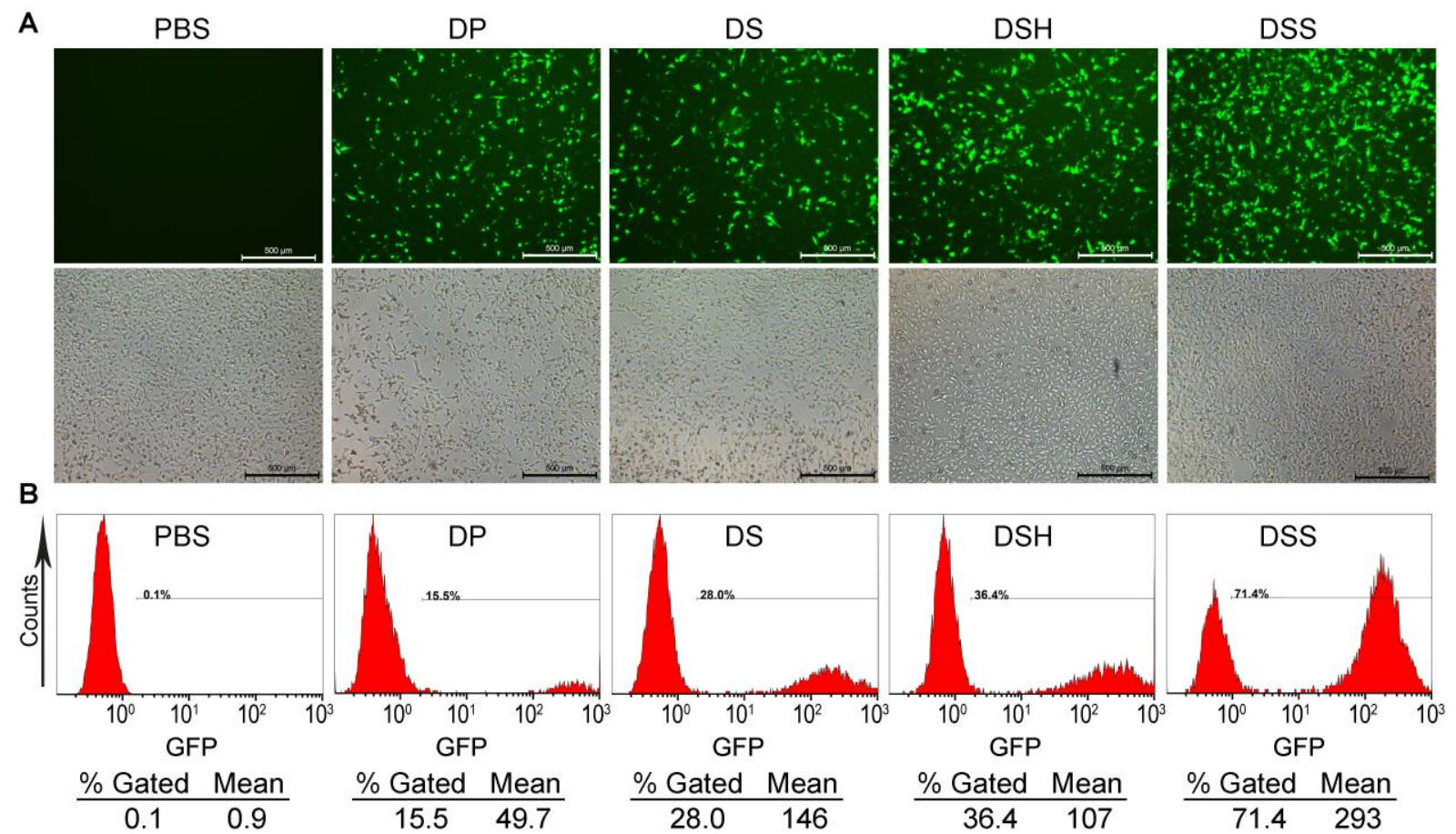

Figure 4. GFP reporter gene expression of gene carriers at their optimized weight ratios on B16F10 cells. (A) Fluorescence images (Row 1) and bright field (Row 2, magnification $50 \times$ ). (B) GFP-positive cells (\%) were determined by flow cytometry. (DNA concentration is 2 $\mu \mathrm{g} / \mathrm{mL}$. DP: PEI/DNA = 1.33; DS: OEI-SS $/$ DNA = 10; DSH: OEI-SS $/$ /DNA = 10, HA/DNA $=1 ;$ DSS: $\left.\mathrm{OEI}-\mathrm{SS}_{\mathrm{x}} / \mathrm{DNA}=10, \mathrm{HA}-\mathrm{SS}-\mathrm{COOH} / \mathrm{DNA}=2 ; \mathrm{w} / \mathrm{w}\right)$

To further verify the potential of DSS for gene delivery, transfection with a GFP reporter gene was conducted in B16F10 and NIH3T3 cells. Fluorescent microscopy revealed the GFPtransfected cells with bright green fluorescent spots (Figure 4A). Flow cytometry analysis was conducted to determine the percentage of transfected cells, and results similar to the microscopy were obtained (Figure 4B). Strikingly, the DSS group (71.4\% GFP-positive cells) showed the strongest green fluorescence in $\mathrm{B} 16 \mathrm{~F} 10$ cells, indicating that DSS were beneficial for introducing exogenous genes into tumor cells. However, the improvement of DSSmediated transfection was not observed in CD44-negative NIH3T3 cells (Figure S4), which corresponds to the luciferase expression results. Moreover, through the visual inspection of cell morphology and density from the bright-field images, the DSH and DSS groups resulted in healthy B16F10 cells with a greater cell density. After being transfected with DP and DS, numerous cells detached from the culture plate and the cell density decreased. These 
observations demonstrated that DSS and DSH did not have significant toxicity at the working concentrations.



Figure 5. Cellular uptake of Cy5-labeled gene carriers (red) after incubation with cells using medium supplemented with serum for 4 hours. (A) B16F10, (B) HepG2, and (C) pretreatment of HepG2 cells with free HA. FITC-phalloidin (green) and DAPI (blue) were used to stain Factin and cell nuclei, respectively. Scale bars are $25 \mu \mathrm{m}$. (DP: PEI/DNA $=1.33$; DS: OEI$\mathrm{SS}_{\mathrm{x}} / \mathrm{DNA}=10 ; \mathrm{DSH}: \mathrm{OEI}_{-\mathrm{SS}} / \mathrm{DNA}=10, \mathrm{HA} / \mathrm{DNA}=1 ; \mathrm{DSS}^{\mathrm{O}} \mathrm{OEI}-\mathrm{SS} \mathrm{X}_{\mathrm{x}} / \mathrm{DNA}=10, \mathrm{HA}-\mathrm{SS}-$ $\mathrm{COOH} / \mathrm{DNA}=2 ; \mathrm{w} / \mathrm{w}$ )

\subsection{Cellular Uptake and Intracellular Trafficking}

The uptake profile of DSS was assessed using CLSM (Figure 5A and B). After the cells were incubated with different gene carriers in the medium supplemented with $10 \%$ FBS for 4 hours, Cy5-labeled DSS and DSH nanocarriers were efficiently internalized into tumor cells (B16F10 and HepG2). Much stronger red pixels were observed inside cells compared with cells incubated with DP or DS. More importantly, no obvious differences could be found between cells incubated with DSH and DSS. Previous findings suggested that modification of HA with a certain number of disulfide linkages cannot influence CD44-mediated 
endocytosis $^{[25]}$. Because PEI/DNA nanocarriers were engulfed by the cells mainly through macropinocytosis $^{[4 b, 26]}$, a free HA competition assay was used to further confirm the hypothesis about receptor-mediated endocytosis of HA derivative-coated nanocarriers on cells overexpressing CD44. Cells were pretreated with an excess amount of free HA and were then incubated with DSS and DSH. As shown in Figure 5C, free HA significantly inhibited the cellular uptake of DSS and DSH; however, the uptake of DS and DP in HepG2 cells was not reduced by pretreating with free HA. The above results reveal the feasibility of HA-mediated internalization of DSS into cancer cells overexpressing CD44.

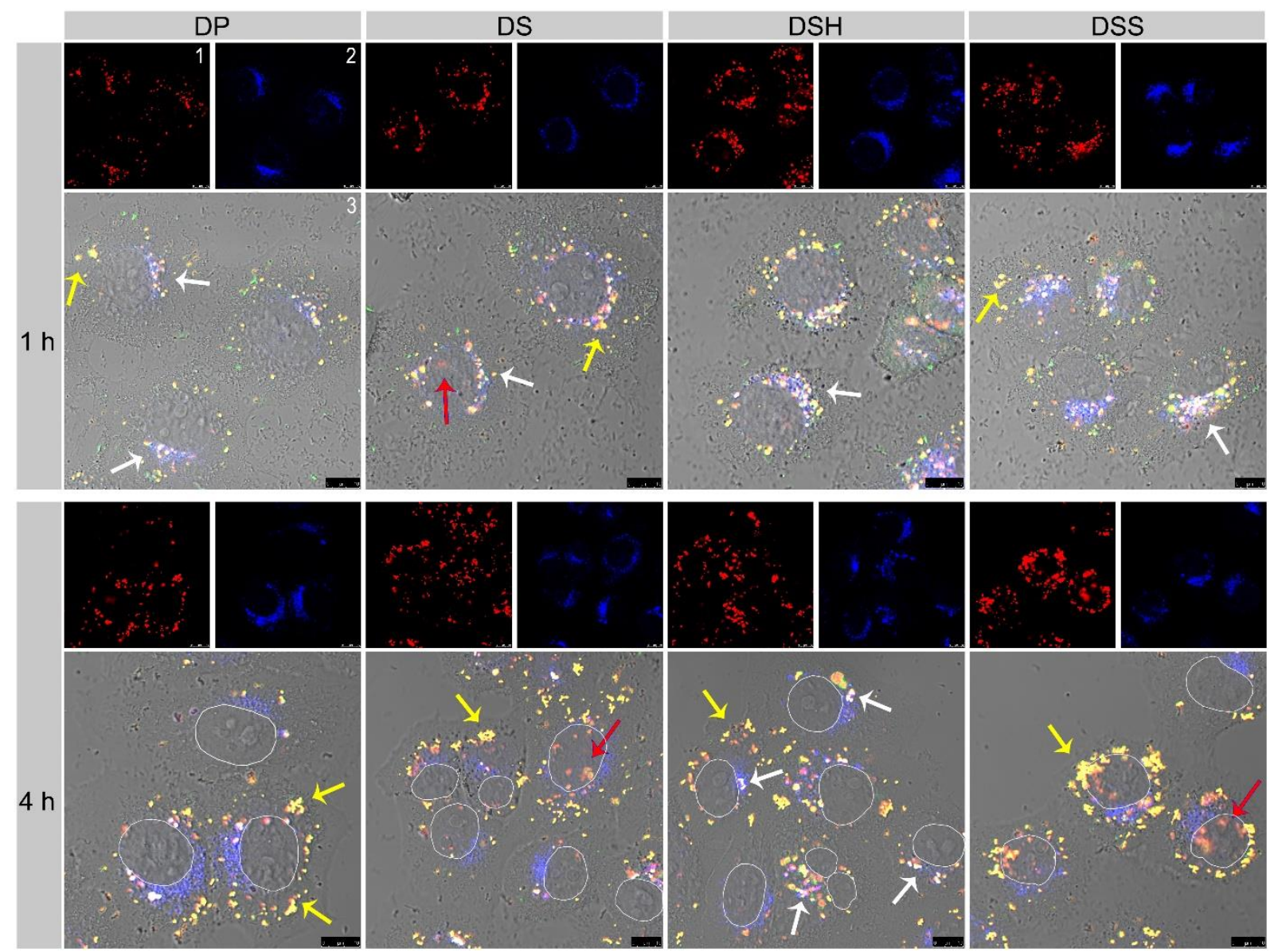

Figure 6. Confocal laser scanning microscope observation of intracellular delivery of DP, DS, DSH and DSS nanocarriers in HepG2 cells at different times. The nanocarriers were prepared with FITC-labeled OEI-SSx or PEI (green) and Cy5-labeled DNA (red). LysoTracker (blue) was used to stain the acidic late endosomes and lysosomes. 1: Cy5 channel; 2: LysoTracker channel; 3: overlay of 1 (Cy5), 2 (LysoTracker) and FITC channel. White arrows signify the coincidence of the endosomes/lysosomes and the nanocarriers. Yellow arrows indicate the nanocarriers escaping from the endosomes/lysosomes into the cytoplasm. White circles indicate the position of the nuclei. Red arrows show released DNA and suggest entry into the nucleus. Scale bar $=10 \mu \mathrm{m}$. (DP: PEI/DNA = 1.33; DS: OEI-SS $/$ DNA = 10; DSH: OEI$\mathrm{SS}_{\mathrm{x}} / \mathrm{DNA}=10, \mathrm{HA} / \mathrm{DNA}=1 ; \mathrm{DSS}:$ OEI-SS $\mathrm{x} / \mathrm{DNA}=10, \mathrm{HA}-\mathrm{SS}-\mathrm{COOH} / \mathrm{DNA}=2 ; \mathrm{w} / \mathrm{w}$ ) 
For PEI/DNA polyplexes, the prime approach of uptake is macropinocytosis, while CD44 receptor-mediated endocytosis is also involved for DSH and DSS nanocarriers. Because macropinocytosis is the endocytic pathway that is advantageous in endosomal escape, receptor-mediated endocytosis always results in lysosomal degradation. ${ }^{[26]}$ Hence, the intracellular trafficking of the nanocarriers was observed by CLSM using Cy5-labeled DNA (red), FITC-labeled polycations (green), and LysoTracker (blue) marked late endosomes/lysosomes. As shown in Figure 6, after one hour of incubation, strong white pixels could be observed in DP, DS, and DSH as well as DSS-treated cells, which were generated from the colocalization of the yellow fluorescence nanocarriers with the blue endosome/lysosome dyes. No fluorescence pixels were ever detected in the nuclei, but rather, rare, red fluorescence pixels of the DS group were detected in the nuclei. Four hours later, part of the DSH was still sequestered in the endosomes/lysosomes, as reflected by the strong white pixels, whereas most of the yellow DSS dots were separated from the blue LysoTracker as in the DP and DS groups. It is noteworthy that the strong fluorescence signals from the DS and DSS groups detected in the nuclear regions were mainly detected as red fluorescence. We therefore concluded that DNA was in a decondensed form and successfully escaped from the endosomes.

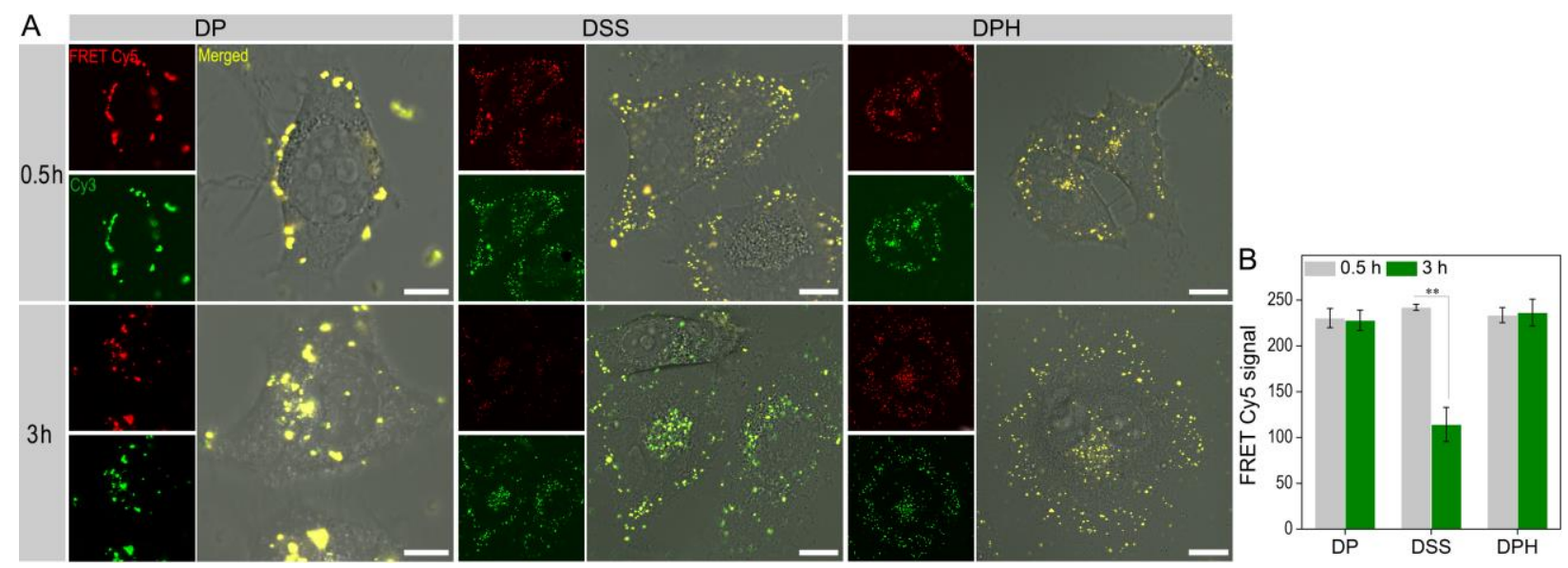

Figure 7. (A) Intracellular visualization of FRET between $\mathrm{Cy} 3$ and $\mathrm{Cy} 5$ dual-labeled DNA nanocarriers (DP, DSS and DPH) in HepG2 cells at different times. Red: signal of FRET Cy5; Green: Cy3 signal; Yellow: the merged signal of FRET Cy5 and Cy3. Scale bars are $10 \mu \mathrm{m}$. (B) Visualization of FRET Cy5 signal by confocal software $(\mathrm{n}=6, * * p<0.05$ by one-way 
ANOVA, followed by Tukey's post-hoc test). (DP: PEI/DNA $=1.33$; DSS: OEI-SS $/$ DNA = 10, HA-SS-COOH/DNA = 2; DPH: PEI/DNA = 1.33, HA/DNA = 1; w/w)

\subsection{The Stimulus Unpacking of DSS Nanocarriers}

It is highly advantageous to employ a FRET technique to illustrate the dynamics of nucleic acids in the delivery process. ${ }^{[8 d, 27]}$ FRET imaging was performed to further validate whether the multi-responsive "turn-on" design was beneficial for stimulus unpacking of DSS and decondensation of DNA. HepG2 cells were incubated with DSS, DPH and DP generated from Cy5 and Cy3 dual-labeled DNA. To distinguish the Cy3 signal from the FRET-mediated Cy5, the Cy3 signal was pseudocolored green. After a 30-min incubation, we observed several yellow clusters in the DSS, DPH and DP groups (Figure 7A), indicating that the red FRETmediated Cy5 fluorescence mainly overlapped the green $\mathrm{Cy} 3$ fluorescence, suggesting a tight package status of carriers and nucleic acids at the early transfection stage. Even after three hours of incubation, many yellow clusters were still observed in both the DP and DPH groups coming from the strong FRET-mediated Cy5 signal co-localized with the Cy3 signal, which demonstrated the package status of the DNA/PEI core and the condensation form of DNA. Whereas little red signal could be detected in the DSS groups, a considerable amount of green fluorescence was expected to be distributed in the cytosol and nuclei. Compared to the DP and DPH groups, the value of the FRET-mediated Cy5 signal for the DSS was obviously decreased $(p<0.05$, Figure 7B), revealing that the DNA was mainly shown to have an unpacking status at the late transfection stage and the consequent inability to excite Cy5. All of the data above demonstrate that the DNA in multi-responsive "turn-on" design DSS could maintain a stable package status at the early transfection stage, whereas the decondensed DNA was ready to transport into nuclei at the late transfection stage. 

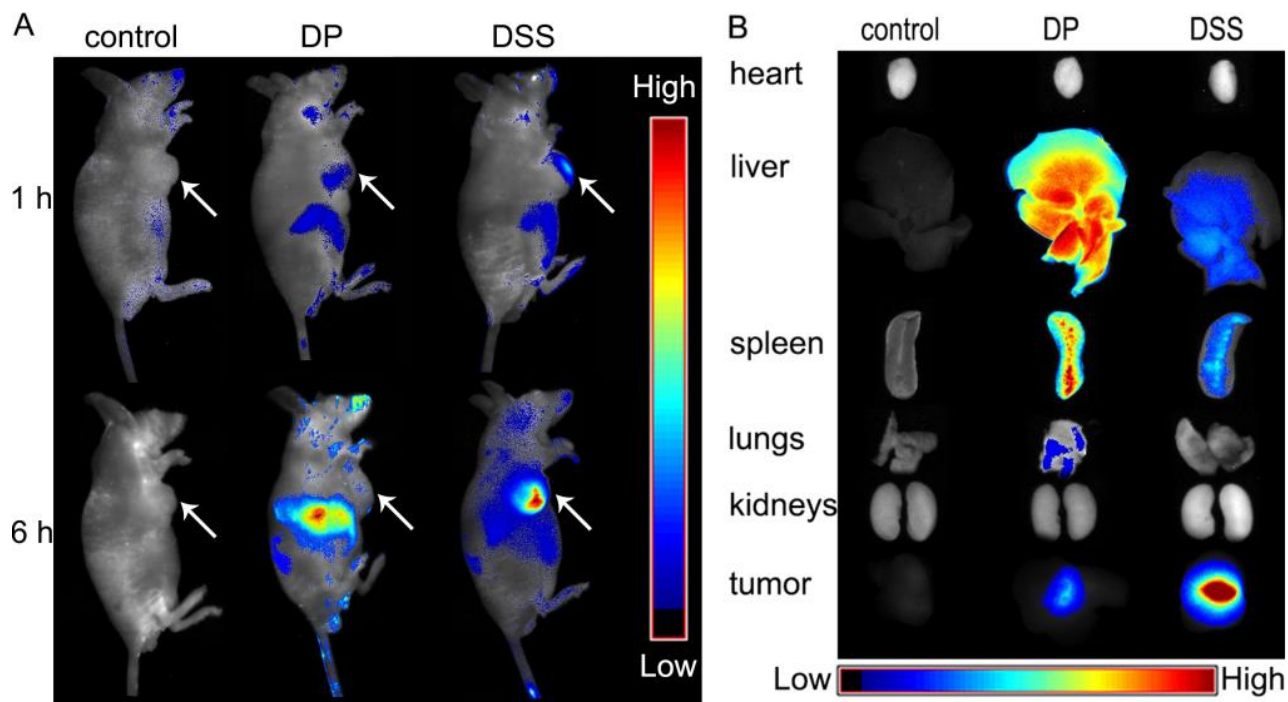

Figure 8. (A) NIRF images of the tumor-bearing nude mice after systemic administration of Cy5.5-labeled gene carriers. Arrows signify the tumor locations. (B) NIRF images of tissues dissected from the mice 6 hours post-administration. (DP: PEI/DNA $=1.33$; DSS: OEI$\left.\mathrm{SS}_{\mathrm{x}} / \mathrm{DNA}=10, \mathrm{HA}-\mathrm{SS}-\mathrm{COOH} / \mathrm{DNA}=2 ; \mathrm{w} / \mathrm{w}\right)$

\subsection{In Vivo Distribution}

In vivo biodistribution and tumor accumulation profiles of the DSS were further monitored using a CRi Maestro EX 3.0 NIRF imaging system. DP or DSS were generated from $50 \mu \mathrm{g}$ of the Cy5.5-labeled plasmid administered intravenously into HepG2 tumor-bearing nude mice, and the NIRF images were taken at 1 and 6 hours. As illustrated in Figure 8A, the fluorescent signals of the DP group could be detected around the liver, tumor and spleen. Among them, the liver showed the strongest fluorescent signal. However, it was interesting to note that strong signal strength from the DSS-treated mice was detected in the liver and tumor one hour post-injection, followed by a gradual enhancement in the signal strength six hours postinjection. Because the tumor sites still showed the strongest fluorescence 6 hours postinjection, it was easy to distinguish tumors from other tissues (liver and spleen). The signal of tissues dissected from the mice was also detected (Figure 8B). The strongest signal from the DSS-treated mice was in the tumor site rather than the liver or the spleen indicating that the DSS had excellent tumor accumulation ability. 

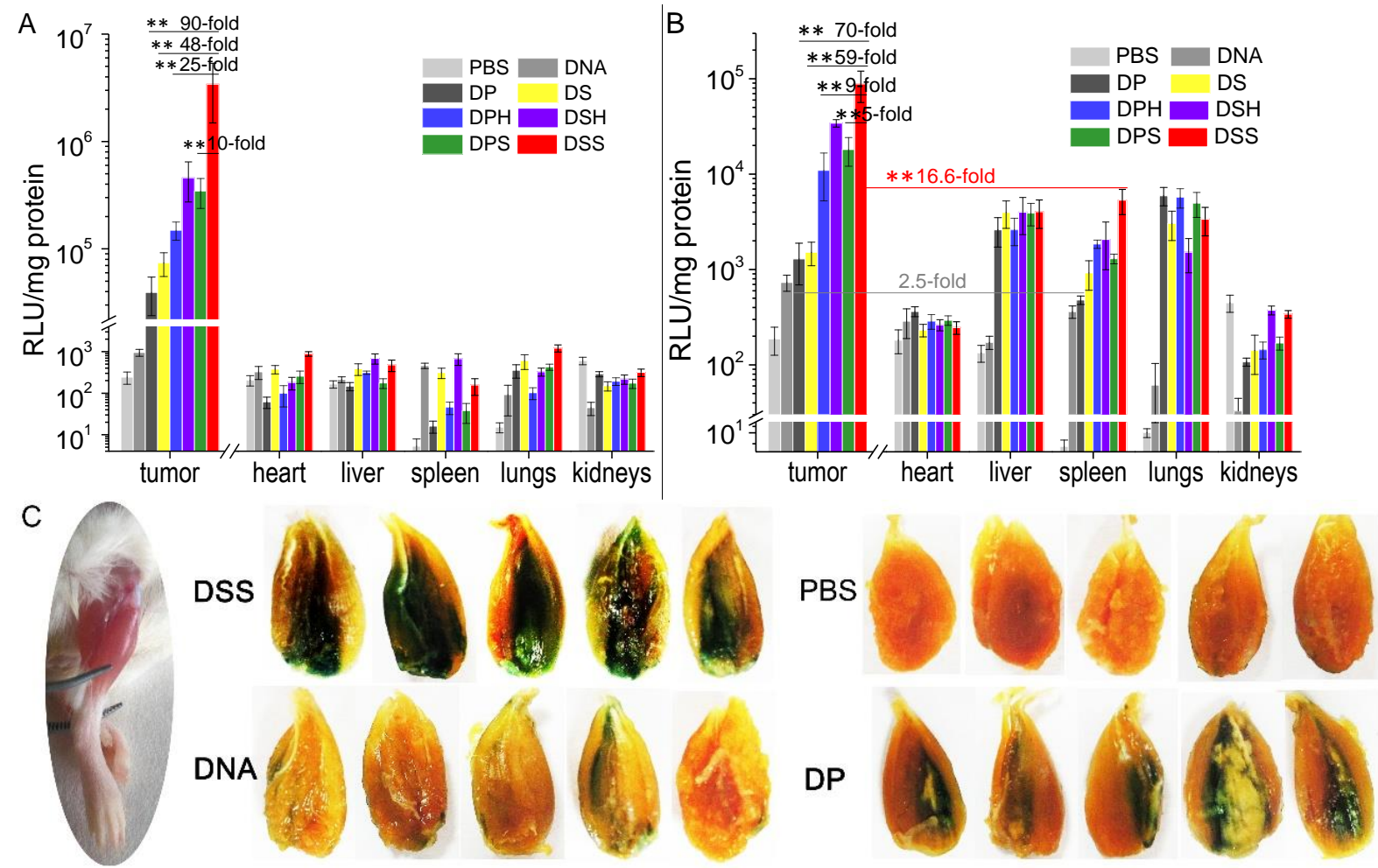

Figure 9. Luciferase activity in the tumors and organs of nude mice after (A) intratumoral and (B) intravenous injection with different gene formulations containing $50 \mu \mathrm{g}$ pCMV-Luc. ( $\mathrm{n}=6$, ** $p<0.05$ by one-way ANOVA, followed by Tukey's post-hoc test) (C) Gene expression in tibialis anterior muscle of $\mathrm{BALB} / \mathrm{c}$ mice after intramuscular injection of different gene formulations containing $10 \mu \mathrm{g}$ pORF-LacZ.

\subsection{In Vivo Gene Transfection}

Encouraged by the excellent tumor accumulation performance of the multi-responsive "turnon" design DSS, in vivo gene delivery of DSS was further investigated in tumor-bearing nude mice. Different nanocarriers containing luciferase-encoding plasmid DNA (pCMV-luc) were injected intratumorally, and the luciferase expression in the main tissues was analyzed 2 days post-injection (Figure 9A). DPH and DPS with the stable PEI/DNA polyplexes core were used as controls for comparison with DSH and DSS, respectively. As expected, DSS showed the strongest transfection efficacy in the tumor and achieved $3.4 \times 10^{6} \mathrm{RLU} \mathrm{mg}^{-1}$ protein. It was approximately 90- and 25-fold stronger than the expression level of the golden standard DP and DPH groups, respectively $(p<0.05)$. Compared with DPS, which has the same detachable HA-SS-COOH envelope, DSS exhibited an almost 10-fold stronger transfection efficiency $(p<0.05)$. DSS was also superior to the DSH group with the same degradable OEI- 
SSx/DNA core $(p<0.05)$. This result indicated that DSS with the degradable OEI-SSx/DNA core and detachable and targeted HA-SS-COOH envelope resulted in significantly improved transfection in the tumor and reduced gene transfection in normal tissues via intratumoral administration.

To investigate the potential of DSS for transfecting the hepatoma after intravenous injection, luciferase expression was evaluated in the same tumor model. As revealed in Figure 9B, luciferase expression was found in the tumor and other tissues, whereas luciferase expression in the heart and kidneys was minimal. The transfection efficiencies in the tumor were much stronger than in other normal organs. Nanocarriers with an HA or HA-SS-COOH envelope could introduce exogenous DNA to the tumor and achieve gene transfection, and the expression level was approximately 200 -fold stronger than that obtained in other tissues (liver, spleen or lungs). Among the different gene nanocarriers, DSS achieved the best gene delivery performance showing a dramatic increase of approximately 70 -fold over the DP group in the tumor while reducing gene expression in the spleen. Interestingly, the gene expression in the DSS and DP groups in the tumor was 16.6- and 2.5-fold greater than in the spleen, respectively. This demonstrates the superiority of DSS in the transfection of tumor tissue.

Intramuscular administration is a promising strategy for gene therapy ${ }^{[28]}$. In this study, intramuscular gene transfection can not only serve as a model to evaluate the effect of gene release and nuclear transport on gene transfection, but also provide an intuitionistic way to investigate the toxicity of DSS in tissue. We carried out gene transfection studies using the LacZ gene via intramuscular injection. Dark blue domains distinctly appeared in the muscular tissue because of the $\beta$-galactosidase expression. As shown in Figure $9 \mathbf{C}$, a large number of $\beta$-galactosidase-positive myofibers were obtained in the DSS-treated muscles. However, a few blue $\beta$-galactosidase-positive myofibers were found in the DP-treated muscles. Hardly 
any blue myofibers were detected in the naked DNA and PBS-treated muscles. A comparison of gene transfer properties of DP and DSS indicated a higher efficiency of DSS in muscles. DP clearly did not have nuclear import capacity and showed inefficient transfection in nondividing skeletal muscle where there is no nuclear envelope breakdown. ${ }^{[29]}$ Thus, transport across the nuclear membrane for muscle cells is a predominant hurdle to non-viral carriers. ${ }^{[30]}$ Since skeletal muscles are CD44 negative and non-dividing, ${ }^{[31]}$ enhancing gene release and nuclear transport of DSS contribute reasonably to successful transgene expression. Moreover, it was interestingly noted that DSS never displayed any detectable inflammation in muscles, whereas severe inflammation was found in the DP-treated muscles. This result could be reasonably ascribed to highly efficient dissociation of the DSS polyplexes and a detachable HA-SS-COOH coating to DNA/OEI-SSx inner polyplexes via electrostatic forces.

\section{Discussion}

Systemic gene delivery is a complicated and multistep process involving numerous biological barriers. Despite substantial efforts devoted to developing various gene carriers for conquering one or several impediments. Exploiting multifunctional carriers that can combatall of the obstacles simultaneously is a formidable challenge. In this study, the multi-responsive "turn-on" DSS nanocarriers (Scheme 1) can respond to the alterations in hyaluronidases and GSH at both the tumor site and the intracellular milieu. This design enabled DSS to remain stable during circulation and to effectively accumulate at the tumor site via systemic administration. Once internalized into the tumor cells by CD44 receptor-mediated endocytosis, the HA-SS-COOH envelope could be degraded stepwise by hyaluronidases at both the tumor site and the intracellular milieu. The nanocarriers further responded to a high concentration of GSH by completely detaching the envelope and disassembling the DNA-encapsulating core. These actions contribute to the endosomal escape and gene release functions to greatly 
enhance nuclear gene delivery. DSS was capable of overcoming multiple transfection barriers that nanocarriers encounter upon systemic administration.

To determine the multi-responsive "turn-on" process of the HA-SS-COOH envelope degradation and detachment as well as the OEI-SSx/DNA inner core dissociation, we measured the changes in the nanocarriers treated with a reductive agent and/or hyaluronidase with respect to the zeta potential, size and morphology. DSS, as it has a well-defined particle size $(164.5 \pm 6.7 \mathrm{~nm})$ and zeta potential $(15.5 \pm 0.6 \mathrm{mV})$, was selected. After incubation with hyaluronidase, the size of the DSS increased. Whereas irregular and aggregated morphology could be observed in the DSS group after further treating with a reductive agent, the zeta potential decreased as well. These observations are most likely due to the collapse of the HASS-COOH envelope by hyaluronidase and the breakdown of disulfide linkages in the envelope as well as the OEI-SS . At the same time, the small pieces of OEI generated from the dissociation of the inner OEI-SSx/DNA core cannot effectively condense the nucleic acid, which is beneficial for on-demand gene release.

Stable and effective nanocarriers through the self-assembly of DNA and polycations typically have a positive surface charge, which, however, can lead to undesirable side effects. Anionic natural polysaccharide hyaluronic acid derivatives serving as the envelope may reduce the non-specific electrostatic association with the cell membrane. In addition, the disulfide crosslinking of OEI-SSx is also beneficial for improving the cell viability of the gene nanocarriers. The potential for gene transfection evaluated using CD44-positive and -negative cells showed that the transfection activities of DSS were increased in CD44-positive cells (HepG2 and B16F10) compared with the DP control group. However, the extremely opposite effects on HA receptor-deficient NIH3T3 cells led to a lower gene expression. The effect of the bioresponsive detachable HA-SS-COOH envelope was critical and resulted in CD44 
receptor-mediated endocytosis and exposing the OEI-SS $/$ /DNA core for endosomal escape. The core was further disassembled by intracellular GSH leading to the release of DNA and the achievement of high transfection as well as low cytotoxicity. The bottleneck for gene delivery is to achieve balance between the protection and release of DNA. Therefore, this procedure is quite beneficial in improving transfection efficiency.

A preliminary investigation of the contribution of the HA and HA-SS-COOH envelope for the uptake of nanocarriers showed that the uptake efficiency of DSS and DSH was improved in CD44-overexpressing cells and can be effectively inhibited by free HA. However, free HA competition did not influence the uptake of DP. The observations above imply that although the greater positive zeta potential of the DP and DS facilitated the electrostatic interaction between the nanocarriers and the negatively charged cell membranes, the biological recognition and affinity proved much more powerful for uptake ${ }^{[5]}$. This fast accumulation profile is a key factor for in vivo application because the contact between target cells and nanocarriers is typically transient in vivo ${ }^{[32]}$. Furthermore, the zeta potential of DSS was 15.5 $\pm 0.6 \mathrm{mV}$, revealing that a certain amount of envelope (envelope/DNA $=1, \mathrm{w} / \mathrm{w}$ ) covered the surface of the OEI-SSx/DNA inner core but still could not shield all of the positive charge. One of the possibilities was that some OEI-SSx head groups were still evident on the surface even after envelope formation, and these groups may have led to macropinocytosis. Therefore, CD44 receptor-mediated endocytosis and macropinocytosis are the main methods for the uptake of DSS. HA derivatives enveloping nanocarriers were concluded to become internalized via macropinocytosis in CD44-negative cells based on the transfection results showing that the luciferase expression of HA derivatives enveloping the nanocarriers did not decrease drastically in NIH3T3 cells. 
Not only internalization but also intracellular trafficking remain formidable obstacles for cancer gene therapy. A further evaluation of DSS for intracellular trafficking in living HepG2 cells has been performed. After being taken up, both DP and DS were able to escape efficiently from endosomes because macropinocytosis always results in endosomal escape ${ }^{[26]}$. Successful endosome escape was also achieved by DSS in HepG2 cells, whereas some DSH was still sequestered in the endosomes/lysosomes, and both of these were taken up via macropinocytosis as well as through a receptor-mediated pathway. This was mainly ascribed to the fact that DSS with a detachable envelope could successfully activate the endosomal escape ability of OEI-SSx. Notably, DNA from both the DS and DSS groups was detected in an unpacking form, which could be primarily attributed to the timely dissociation of DSS and release of the genes by intracellular GSH. The decondensation behavior of DNA inside cells is a key determining factor for improving the gene transfer rate. FRET was also conducted to further validate that the multi-responsive "turn-on" design concept is useful for stimulus unpacking of DSS and decondensation of DNA.

Although some gene carriers can achieve wonderful gene transfection in vitro, the in vivo performance has been proven to be unsatisfactory primarily due to the stability issue of nanocarriers and the presence of the mononuclear phagocyte system (MPS). The MPS consists of dendritic cells, blood monocytes, granulocytes, and tissue-resident macrophages in the liver and spleen that are responsible for clearing, processing, and degrading foreign materials. ${ }^{[33]}$ In vivo biodistribution has shown that the fluorescent signals of the DP group could be detected around the liver, spleen and tumor. The fluorescent signals from the liver and spleen were much stronger than the signals from other tissues, which might be due to the positive surface charge $(+27 \mathrm{mV})$ of DP. When the cationic DP nanocarriers interacted with the blood components, the delivered DP appears mainly in the liver and spleen. Recognized as exogenous objects, DP nanocarriers were readily cleared from systemic circulation by MPS in 
the liver and spleen precluding accumulation in tumor cells. The strongest signal from the DSS group could be detected in the tumor tissue at the 6-hour time point, which emphasizes the favorable tumor accumulation profile of DSS. This result could be assigned to the enhanced permeability and retention effect and the targeting ability of HA-SS-COOH-coated nanocarriers to recognize receptors on HepG2 cells. This result could also be attributed to the fact that anionic HA-SS-COOH enveloped DSS had reduced plasma protein adsorption and a low rate of nonspecific cellular uptake. Fluorescence signals from the DSS group could be detected in the liver site because the liver sinusoidal endothelial cells have abundant HARE receptors $^{[34]}$. Although the fluorescence signal of DP in the spleen was much stronger than the DSS signal at the 6-hour time point after injection, the gene expression of DP in the spleen was much lower than the DSS group 2 days after intravenous administration. Previous studies have demonstrated that the high gene transfection of cationic lipid-protamine-DNA (LPD) complexes can be obtained in the spleen $6 \mathrm{~h}$ after systemic administration but drop very rapidly thereafter. ${ }^{[35]}$ Because the gene expression in the spleen drops very rapidly, the discrepancy between the biodistribution and the gene expression was probably due to the difference in the detection time. For intravenous administrations, the paramount obstacle for in vivo targeted gene delivery is the undesired interactions between gene carriers and blood components or non-target cells. Together, these results qualify multi-responsive "turn-on" design DSS as a promising gene delivery system for collectively conquering multiple biological hurdles that nanocarriers encounter upon intravenous administration.

\section{Conclusions}

In conclusion, we have developed multi-responsive "turn-on" DSS nanocarriers consisting of a hyaluronidase and GSH dual-sensitive HA-SS-COOH envelope and a bioreducible DNA/OEI-SSx inner core for combating biological barriers in non-viral gene delivery. DSS can respond to the alterations in hyaluronidases and GSH at both the tumor site and the 
intracellular milieu. The multi-responsive "turn-on" design enabled DSS to remain stable during circulation and effectively accumulate at the tumor site via systemic administration. Once internalized into the tumor cells by CD44 receptor-mediated endocytosis, the HA-SS$\mathrm{COOH}$ envelope could be degraded stepwise by hyaluronidases at both the tumor site and the intracellular milieu and could further respond to high concentration GSH by completely detaching the envelope and disassembling the DNA-encapsulating core. These multiresponsive features are beneficial for facilitating endosomal escape and unpacking the loaded genes for nuclear delivery. DSS was systematically investigated in vitro and in vivo and was compared with some well-chosen control groups including the insensitive golden standard DNA/PEI (DP), non-enveloping DNA/OEI-SSx (DS) and stable envelope DNA/OEI-SSx/HA (DSH). These results revealed that the tumor accumulation ability, internalization and endosome escape of the DSS nanocarriers, DNA unpacking and nuclear transportation in serum-containing conditions were all remarkably improved by the multi-responsive "turn-on" design, resulting in enormously efficient gene transfection in vitro and in vivo.

\section{Experimental Section}

Chemicals and Reagents: 1-Ethyl-3-(3-dimethylaminopropyl) carbodiimide (EDC), hydroxybenzotriazole (HOBt) and cysteine hydrochloride were from Sinopharm. Hyaluronic acid (HA, MW $1600 \mathrm{KDa}$ ) was ordered from Aladdin. 3-Mercaptopropionic acid, dithiothreitol (DTT), branched polyethyleneimine $25 \mathrm{kDa} \quad$ (PEI), 3,3'disulfanediyldipropanoic acid (DSDPA), oligoethylenimine 800 Da (OEI), and hyaluronidases, as well as antibiotics (streptomycin and penicillin) were from Sigma-Aldrich. 4',6-Diamidino-2-phenylindole (blue, DAPI) and FITC-labeled phalloidin (green) were

obtained from Aldrich. The nucleic acid labeling kit Label $\mathrm{IT}^{\circledR} \mathrm{Cy} 3^{\mathrm{TM}}$ and $\mathrm{Cy} 5^{\mathrm{TM}}$ were purchased from Mirus. LysoTracker DND-22 (Blue) was from Invitrogen. Fetal bovine serum (FBS) and Dulbecco's modified Eagle's medium (DMEM) were commercially available from 
Life Technologies Corporation. The human hepatoma cells HepG2, mouse fibroblast cells NIH3T3 and murine melanoma cells B16F10 were purchased from Shanghai Institutes for Biological Sciences. pGL3 plasmid encoding luciferase and pEGFP plasmid encoding green fluorescent protein were purified with an EndoFree plasmid kit from Qiagen. The pCMV-Luc plasmid was constructed by cloning the luciferase gene from the pGL3 promoter vector into pcDNA 3.1 and then purifying. 3-(4,5-Dimethylthiazol-2-yl)-2,5-diphenyltetrazolium bromide (MTT) was commercially available from Amresco. A BCA Protein Assay Kit and luciferase reporter gene assay kit were obtained from Pierce and Promega, respectively. The preparation of HBG buffer (2-[4-(2-hydroxyethyl)-1-piperazinyl] ethanesulphonic acid (HEPES) $20 \mathrm{mM}, \mathrm{pH}$ 7.4, 5\% glucose) and other buffer solutions was achieved with MilliQ ultrapure water; the rest of the reagents were obtained from Aldrich and used directly.

De Novo Synthesis of OEI-SSx and HA-SS-COOH: The OEI-SS $\mathrm{x}_{\mathrm{x}}$ and HA-SS-COOH were synthesized as in our previous description. ${ }^{[6 a, 36]}$ Briefly, the carboxyl groups of 3,3'disulfanediyldipropanoic acid (DSDPA) were activated using NHS/EDC. The obtained active ester was dissolved in DMSO and mixed with an appropriate amount of OEI (the proportion of OEI and active ester was 1:1.2) under nitrogen for 48 hours. Pure OEI-SS $\mathrm{x}_{\mathrm{x}}$ product was obtained after dialysis (MW cut-off: $7 \mathrm{kDa}$ ) and lyophilization. According to the gel permeation chromatography (GPC) analysis, the MW of OEI-SS $\mathrm{x}_{\mathrm{x}}$ was comparable to PEI 25 kDa.

HA with a 30\% (molar ratio) disulfide modification between the pendant carboxyl group and the backbone was performed as follows. The viscosity average molecular weight (Mv) of the degraded HA after purification and acid degradation was $409 \mathrm{kDa}$. The pendant carboxyl acid moieties of the HA were reacted with cystamine dihydrochloride by activation with HOBt and EDC at a molecular ratio of 3:1. Then, the disulfide bonds in the cystamine functionalized HA 
were cleaved using an excess amount of DTT resulting in the free thiol group modified HA (HA-SH). Subsequently, the obtained HA-SH was further reacted with excess 3mercaptopropionic acid at $25{ }^{\circ} \mathrm{C}$ in a PBS buffer solution for 24 hours. After a thorough dialysis and freeze-drying, HA-SS-COOH with a 30\% molar ratio of carboxyl groups modified with disulfide linkages was obtained. The Ellman's assay ${ }^{[37]}$ and ${ }^{1} \mathrm{H}$ NMR were conducted to monitor the products.

Preparation of DSS Nanocarriers: OEI-SSx, HA-SS-COOH, HA and DNA were separately dissolved in HBG buffer. The OEI-SSx solution was then added to the DNA solution at a fixed concentration (100 ng $\left.\mu \mathrm{L}^{-1}\right)$ to generate DNA/OEI-SSx (DS) binary polyplexes at a weight ratio of 10 . The DS polyplexes were maintained for $20 \mathrm{~min}$ at room temperature, and then the DS polyplexes were added to the HA-SS-COOH solution at HA-SS-COOH/DNA ratios ranging from 0.2 to 5, creating DNA/OEI-SSx/HA-SS-COOH (DSS) ternary polyplexes. DNA/OEI-SSx/HA (DSH) ternary polyplexes were fabricated as above. Unless otherwise specified, most DSS nanocarriers used in experiments were prepared at an envelope to DNA ratio of two.

Stability of DSS in the Presence of GSH and Hyaluronidase: To evaluate the stability of the DSS in the reductive environment and in the presence of hyaluronidase, the DSS nanocarriers were evaluated using dynamic light scattering (DLS) and transmission electron microscopy (TEM). The nanocarriers with $3 \mu \mathrm{g} \mathrm{mL}^{-1}$ DNA were prepared and incubated with $10 \mathrm{mM}$ DTT for $30 \mathrm{~min}$ at $37^{\circ} \mathrm{C}$ prior to estimating the size distribution and zeta potential. At the same time, the particle size changes of the DSS nanocarriers (the weight ratios of OEI-SS $\mathrm{x}_{\mathrm{x}}$ and HASS-COOH to DNA were 10 and 2, respectively) incubated with different concentrations of hyaluronidase $\left(0,60\right.$ and 120 unit $\left.\mathrm{mL}^{-1}\right)$ in acetate buffer $\left(\mathrm{pH} 5.5,37^{\circ} \mathrm{C}\right)$ were recorded every 20 min. In addition, changes in the DSS nanoparticle morphology were investigated by TEM 
(Tecnai G2 F20 S-TWIN, FEI Company) after treatment with hyaluronidase (120 units $\left.\mathrm{mL}^{-1}\right)$ and/or DTT $\left(10 \mathrm{mM}\right.$ ) for $30 \mathrm{~min}$ at $37^{\circ} \mathrm{C}$. Untreated DSH (the weight ratios of OEI-SS $\mathrm{x}$ and HA to DNA were 10 and 2, respectively) and DSS were used as controls.

Cell Culture and Cytotoxicity Assay: Cells were propagated to confluence in DMEM-HG medium supplemented with 10\% FBS and penicillin-streptomycin. Cells were cultured at $37^{\circ} \mathrm{C}$ in a humidified atmosphere of $5 \%$ carbon dioxide and were harvested with $0.25 \%$ trypsin and $0.03 \%$ EDTA. The cell viability with various nanocarriers was evaluated using the MTT assay. DP (the weight ratio of PEI to DNA was 1.33), DS (the weight ratio of OEI-SSx to DNA was 10), DSS and DSH nanocarriers with different HA-SS-COOH or HA to DNA weight ratios were added to reach $200 \mathrm{ng}$ DNA in each well. After 1 day, $10 \mu \mathrm{L}$ of the MTT solution $\left(5 \mathrm{mg} \mathrm{mL}^{-1}\right)$ was added to each well. After another four-hour incubation, $150 \mu \mathrm{L}$ of DMSO was used to dissolve the formazan crystal. The cytotoxicity of the nanocarriers was detected using a microplate reader (Bio-Rad) at $560 \mathrm{~nm}$.

In Vitro Transfection: The gene transfer properties of the multi-responsive "turn-on" DSS nanocarriers were investigated using HepG2 (CD44-positive), B16F10 (CD44-positive) and NIH3T3 (CD44-negative) cell lines, respectively. For the luciferase assay, $1 \times 10^{4}$ cells per well were seeded in 96-well plates in $100 \mu \mathrm{L}$ DMEM containing 10\% FBS. The nanocarriers (weight ratios of nanocarriers: DP $(\mathrm{PEI} / \mathrm{DNA}=1.33)$, DS $(\mathrm{OEI}-\mathrm{SSx} / \mathrm{DNA}=10), \mathrm{DSH}(\mathrm{OEI}-$ SSx/DNA = 10, HA/DNA = 1), DSS (OEI-SSx/DNA = 10, HA-SS-COOH/DNA = 2), DPH $(\mathrm{PEI} / \mathrm{DNA}=1.33, \mathrm{HA} / \mathrm{DNA}=1), \mathrm{DPS}(\mathrm{PEI} / \mathrm{DNA}=1.33, \mathrm{HA}-\mathrm{SS}-\mathrm{COOH} / \mathrm{DNA}=1))$ were added at the indicated OEI-SS X $_{\mathrm{DNA}}(10)$ and HA-SS-COOH or HA to DNA (0.2 5) ratios at a pGL3 plasmid concentration of $200 \mathrm{ng}$ well ${ }^{-1}$ either with or without $10 \%$ FBS. After 4 hours of incubation, the transfection medium was replaced with fresh medium and incubated for an additional day. Then, the transfected cells were harvested, washed and lysed. A microplate 
reader was used to measure the luciferase activity and normalized to milligrams of protein, and the average and standard deviation from triplicate transfections were determined.

For the pEGFP transfection experiments, $3 \times 10^{5}$ B16 and NIH3T3 cells were seeded in 6-well plates in $2 \mathrm{~mL}$ DMEM containing 10\% FBS. DSS nanocarriers of OEI-SS $/$ DNA $=10$ and HA-SS-COOH/DNA $=2$ were selected to compact with pEGFP. DP, DS, DSH and DSS nanocarriers were added to $2 \mu \mathrm{g}$ of the pEGFP-C1 plasmid per well without FBS. After 4 hours of transfection, the medium was replaced with fresh medium and incubated for an additional 2 days. An inverted fluorescence microscope was used to evaluate the GFPpositive cells. To quantitatively determine the GFP transfection efficiency, pEGFPtransfected cells were washed twice with PBS (pH 7.4), harvested using trypsin, and washed again with PBS containing 3\% serum; then, the cells were resuspended in PBS for FACS analysis.

Uptake and Intracellular Trafficking: The molecular targeting ability of the DSS nanocarriers was evaluated using a confocal laser scanning microscope. Briefly, $2 \times 10^{4}$ HepG2 and B16 cells were seeded in 35-mm confocal dishes $(\Phi=15 \mathrm{~mm})$, and 30\% Cy5-labeled DNA nanocarriers were added to the cells containing 300 ng DNA per well with $10 \%$ serum, followed by four hours of incubation. At the same time, competitive binding of CD44 receptors between the HA-envelope nanocarriers and an excess amount of free HA was performed in HepG2 cells. After pretreatment with $0.2 \% \mathrm{w} / \mathrm{v}$ free HA for 1.5 hours, the HepG2 cells were incubated with different gene carriers in medium containing $10 \%$ FBS for an additional 4 hours. The cells were then washed twice with PBS (pH 7.4) and fixed with 4\% formaldehyde. DAPI (blue, $5 \mu \mathrm{g} \mathrm{mL}^{-1}$ ) and FITC-labeled phalloidin (green, $1 \mu \mathrm{g} \mathrm{mL}^{-1}$ ) were used to stain cell nuclei and the actin cytoskeleton, respectively. Then, $5 \mathrm{mM}$ HEPES containing $20 \mathrm{U} / \mathrm{ml}$ of heparin sodium was used to wash cells to remove the gene carriers that 
attach to the cell surface. The intracellular localization of DNA carriers was observed using CLSM (Leica TCS SP5) in which the fluorescent probes of DAPI, FITC and Cy5 were excited at $364 \mathrm{~nm}, 495 \mathrm{~nm}$ and $633 \mathrm{~nm}$, respectively.

Moreover, the endosomal/lysosomal escape and nuclear localization of various nanocarriers (DP, DS, DSH and DSS) were also observed using CLSM. HepG2 cells were incubated with gene carriers prepared with Cy5-labeled DNA and FITC-labeled polycations for the indicated time intervals. Then, the lysosomes were stained with $75 \mathrm{nM}$ LysoTracker Blue at $37^{\circ} \mathrm{C}$ for $30 \mathrm{~min}$. To thoroughly remove the gene carriers bound on the cell surface before confocal observation, a HEPES solution containing heparin sodium was used to wash cells to remove the nanocarriers attached to the cell surface. Fluorescent LysoTracker Blue probe, FITC and Cy5 were excited at $373 \mathrm{~nm}, 495 \mathrm{~nm}$ and $633 \mathrm{~nm}$, respectively.

Fluorescence Resonance Energy Transfer Technique: Fluorescence resonance energy transfer (FRET) imaging was carried out to study the package status and stimulus-responsive release of DNA from DSS nanocarriers in the reduced milieu. To monitor the FRET phenomenon, Cy5 and Cy3 dual-labeled plasmids were used to generate DP, DPH and DSS nanocarriers. The average fluorescent dye densities were 1 dye per 380 plasmid base pairs. Then, $2 \times 10^{4}$ HepG2 cells were seeded in a confocal dish. DP, DPH and DSS nanocarriers were added to the cells containing $200 \mathrm{ng}$ DNA per well with serum. After incubation for the indicated time intervals, the medium was removed. The gene carriers that attach to the cell surface were removed by washing with HEPES solution containing heparin sodium. The stimulus unpacking of the indicated gene carriers and decondensation behavior of the DNA were acquired using CLSM. The emission signals of Cy3 and FRET-Cy5 were observed in the Cy3 (dichroic mirror 565-620 nm) and Cy5 (dichroic mirror 655-755 nm) channels, respectively, through excitation with a 543-nm laser. 
In Vivo Real-Time Biodistribution: All animal experiments were conducted following the ethics of Sichuan University and the NIH guidelines for research animals. BALB/c nude mice were from the National Rodent Laboratory Animal Resources and were maintained under specific pathogen-free (SPF) conditions. A 50- $\mu$ l aliquot of sterile physiological saline containing $10^{6}$ HepG2 cells was subcutaneously injected into the axillary of five-week-old male mice $(25 \pm 3 \mathrm{~g})$. When the volume $\left(0.5 \times\right.$ major axis $\times$ minor axis $\left.^{2}\right)$ of the hepatoma tumors achieved approximately $100 \mathrm{~mm}^{3}$, they were subjected to the biodistribution study. Non-envelope or HA-envelope nanocarriers generated from $50 \mu \mathrm{g}$ of Cy5.5-labeled plasmids were injected intravenously into mice. PBS saline was used as control. Biodistribution and tumor accumulation profiles were investigated using a CRi Maestro EX 3.0 near infrared fluorescence (NIRF) imaging system. At $6 \mathrm{~h}$ post-intravenous injection, the mouse organs and tumors were removed. Fluorescence signals for the Cy5.5-labeled nanocarriers in the dissected tissues were detected. The results were analyzed using the CRI Maestro measurement software.

In Vivo Gene Transfection: Mice with a tumor volume of approximately $100 \mathrm{~mm}^{3}$ were randomly divided into 7 groups of 6 mice per group. For intratumoral injection transfection, naked DNA, DP, DPH, DPS, DSH, or DSS formulations containing $15 \mu \mathrm{g}$ of pCMV-Luc were injected into the tumors. PBS saline was used as the blank control. For intravenous injection transfection, DP (the weight ratio of PEI to DNA was 0.8), DPH or DPS (the weight ratios of PEI and HA derivatives to DNA were 0.8 and 1, respectively), DS (the weight ratio of OEI-SSx to DNA was 6), DSH, or DSS (the weight ratios of OEI-SSx and HA derivatives to DNA were 6 and 1, respectively) formulations containing $50 \mu \mathrm{g}$ pCMV-Luc were intravenously administered to mice. The mice were sacrificed after 2 days; the tissues were 
resected and homogenized in lysis buffer. The supernatant was used to quantify the transfection efficiency after centrifugation.

For intramuscular injection transfection, six-week-old male BALB/c mice were used to evaluate the gene transfection ability of DSS in muscle. To do this, $50 \mu 1$ DNA, DS, DP, DSH or DSS formulations containing $10 \mu \mathrm{g}$ pORF-LacZ were injected directly into the tibialis anterior muscles after removing the hair. PBS was used as the control. The muscles were harvested $72 \mathrm{~h}$ post-injection; the expression of $\beta$-galactosidase was evaluated using the Beyotime $\beta$-galactosidase reporter gene assay kit and photographed with a SONY camera.

Statistical Analysis: All experiments used at least six independent samples, and each measurement was performed in triplicate. Data are reported as mean values \pm standard deviation. *Significance in Figures 2 and 3 was determined using two-way ANOVA followed by Tukey's post hoc test. **Significance in Figures 1, 7 and 9 was evaluated using one-way ANOVA followed by Tukey's post-hoc test. All analyses were performed with SPSS 19.0 for Windows. $P<0.05$ was considered statistically significant.

Supporting Information

Supporting Information is available from the Wiley Online Library or from the author.

\section{Acknowledgements}

This work was financially supported by National Natural Science Foundation of China (51133004, 81361140343, 31500810 and 31271020), the Joint Sino-German Center for Research Promotion (GZ905), the Young Scholar Program of Sichuan University (2015SCU11038), and the Foundation for Talent Introduction from Sichuan University (YJ201464). 
[1] a) R. M. Pearson, H.-j. Hsu, J. Bugno, S. Hong, MRS Bull. 2014, 39, 227; b) E. Wagner, Acc. Chem. Res. 2012, 45, 1005.

[2] a) R. C. Münch, A. Muth, A. Muik, T. Friedel, J. Schmatz, B. Dreier, A. Trkola, A. Plückthun, H. Büning, C. J. Buchholz, Nat. Commun. 2015, 6; b) M. Cully, Nat. Rev. Drug Discov. 2014, 13, 879; c) E. Blanco, H. Shen, M. Ferrari, Nat. Biotech. 2015, 33, 941.

[3] a) H. Maeda, J. Wu, T. Sawa, Y. Matsumura, K. Hori, J. Controlled Release 2000, 65, 271; b) J. Fang, H. Nakamura, H. Maeda, Adv. Drug Deliv. Rev. 2011, 63, 136.

[4] a) E. Fleige, M. A. Quadir, R. Haag, Adv. Drug Deliv. Rev. 2012, 64, 866; b) S.-F. Peng, M. T. Tseng, Y.-C. Ho, M.-C. Wei, Z.-X. Liao, H.-W. Sung, Biomaterials 2011, 32, 239.

[5] P. Xu, S. Y. Li, Q. Li, E. A. Van Kirk, J. Ren, W. J. Murdoch, Z. Zhang, M. Radosz, Y. Shen, Angew. Chem. 2008, 120, 1280.

[6] a) G. Cheng, Y. He, L. Xie, Y. Nie, B. He, Z. Zhang, Z. Gu, Int. J. Nanomed. 2012, 7, 3991; b) D. Yue, G. Cheng, Y. He, Y. Nie, Q. Jiang, X. Cai, Z. Gu, J. .Mater. Chem. B 2014, 2, 7210; c) H. Yu, V. Russ, E. Wagner, Aaps J. 2009, 11, 445; d) X. Cai, R. Jin, J. Wang, D. Yue, Q. Jiang, Y. Wu, Z. Gu, ACS Appl. Mater. Interfaces 2016, 8, 5821.

[7] R. Kircheis, L. Wightman, E. Wagner, Adv. Drug Deliv. Rev. 2001, 53, 341.

[8] a) S. J. Tseng, Z. X. Liao, S. H. Kao, Y. F. Zeng, K. Y. Huang, H. J. Li, C. L. Yang, Y. F. Deng, C. F. Huang, S. C. Yang, P. C. Yang, I. M. Kempson, Nat. Commun. 2015 6, 6456; b) T. Nomoto, S. Fukushima, M. Kumagai, K. Machitani, Arnida, Y. Matsumoto, M. Oba, K. Miyata, K. Osada, N. Nishiyama, K. Kataoka, Nat. Commun. 2014, 5; c) S.-j. Park, W. Park, K. Na, Adv. Funct. Mater. 2015, 25, 3472; d) P.-W. Lee, S.-H. Hsu, J.-S. Tsai, F.-R. Chen, P.J. Huang, C.-J. Ke, Z.-X. Liao, C.-W. Hsiao, H.-J. Lin, H.-W. Sung, Biomaterials 2010, 31, 2425.

[9] a) X.-Z. Yang, J.-Z. Du, S. Dou, C.-Q. Mao, H.-Y. Long, J. Wang, ACS Nano 2012, 6, 771; b) L. Kong, C. S. Alves, W. Hou, J. Qiu, H. Mohwald, H. Tomas, X. Shi, ACS Appl. Mater. Interfaces 2015, 7, 4833; c) L. He, L. Feng, L. Cheng, Y. Liu, Z. Li, R. Peng, Y. Li, L. Guo, Z. Liu, ACS Appl. Mater. Interfaces 2013, 5, 10381; d) M. Panagiotis, C. Zhang, B. Sneha, O. Yumin, L. Seulki, C. G. Eberhart, G. F. Woodworth, S. J. Soo, H. Justin, Adv. Healthcare Mater. 2015, 4, 1023.

[10] H. S. Han, T. Thambi, K. Y. Choi, S. Son, H. Ko, M. C. Lee, D. G. Jo, Y. S. Chae, Y. M. Kang, J. Y. Lee, J. H. Park, Biomacromolecules 2015, 16, 447.

[11] T. Kurosaki, T. Kitahara, S. Fumoto, K. Nishida, J. Nakamura, T. Niidome, Y. Kodama, H. Nakagawa, H. To, H. Sasaki, Biomaterials 2009, 30, 2846.

[12] X. Liu, J. Xiang, D. Zhu, L. Jiang, Z. Zhou, J. Tang, X. Liu, Y. Huang, Y. Shen, Adv. Mater. 2016, 28, 1743.

[13] H. Hatakeyama, H. Akita, H. Harashima, Adv. Drug Deliv. Rev. 2011, 63, 152.

[14] Y. Wang, L. Miao, A. Satterlee, L. Huang, Adv. Drug Deliv. Rev. 2015, 87, 68.

[15] a) S. Uthaman, S. Zheng, J. Han, Y. J. Choi, S. Cho, V. D. Nguyen, J. O. Park, S. H. Park, J. J. Min, S. Park, Adv. Healthcare Mater. 2016, 5, 288; b) S. Wang, M. Cao, X. Deng, X. Xiao, Z. Yin, Q. Hu, Z. Zhou, F. Zhang, R. Zhang, Y. Wu, Adv. Healthcare Mater. 2015, 4, 281; c) D. Bang, T. Lee, J. Choi, Y. Park, E. Kim, Y. M. Huh, S. Haam, Adv. Healthcare Mater. 2015, 4, 255.

[16] T. Jiang, Z. Zhang, Y. Zhang, H. Lv, J. Zhou, C. Li, L. Hou, Q. Zhang, Biomaterials 2012, 33, 9246.

[17] M. Rajan, V. Raj, A. A. Al-Arfaj, A. Murugan, Int. J. Pharm. 2013, 453, 514. 
[18] a) K. Y. Choi, H. Y. Yoon, J.-H. Kim, S. M. Bae, R.-W. Park, Y. M. Kang, I.-S. Kim, I. C. Kwon, K. Choi, S. Y. Jeong, K. Kim, J. H. Park, ACS Nano 2011, 5, 8591; b) Z. Chen, Z. Li, Y. Lin, M. Yin, J. Ren, X. Qu, Chemistry 2013, 19, 1778.

[19] R. Stern, M. J. Jedrzejas, Chem. Rev. 2006, 106, 818.

[20] E. J. Franzmann, G. L. Schroeder, W. J. Goodwin, D. T. Weed, P. Fisher, V. B. Lokeshwar, Int. J. Cancer 2003, 106, 438.

[21] G. Saito, J. A. Swanson, K.-D. Lee, Adv. Drug Deliv. Rev. 2003, 55, 199.

[22] Y. Yamada, M. Hashida, H. Harashima, Biomaterials 2015, 52, 189.

[23] J. Yao, Y. Fan, R. Du, J. Zhou, Y. Lu, W. Wang, J. Ren, X. Sun, Biomaterials 2010, $31,9357$.

[24] a) R. E. Eliaz, F. C. Szoka, Cancer Res. 2001, 61, 2592; b) V. M. Platt, F. C. Szoka Jr, Mol. Pharm. 2008, 5, 474.

[25] G. Jiang, K. Park, J. Kim, K. S. Kim, S. K. Hahn, Mol. Pharm. 2009, 6, 727.

[26] S. Grosse, Y. Aron, G. Thévenot, D. François, M. Monsigny, I. Fajac, J. Gene Med. 2005, 7, 1275.

[27] a) S. M. Shaheen, H. Akita, A. Yamashita, R. Katoono, N. Yui, V. Biju, M. Ishikawa, H. Harashima, Nucleic Acids Res. 2011, 39, e48; b) E.-Y. Chuang, C.-C. Lin, K.-J. Chen, D.H. Wan, K.-J. Lin, Y.-C. Ho, P.-Y. Lin, H.-W. Sung, Biomaterials 2016, 93, 48.

[28] C. H. Evans, J. Huard, Nat. Rev. Rheumatol. 2015, 11, 234.

[29] S. Brunner, E. Fürtbauer, T. Sauer, M. Kursa, E. Wagner, Mol. Ther. 2002, 5, 80.

[30] D. W. Pack, A. S. Hoffman, S. Pun, P. S. Stayton, Nat. Rev. Drug Discov. 2005, 4, 581.

[31] Z. Wang, T. Zhu, C. Qiao, L. Zhou, B. Wang, J. Zhang, C. Chen, J. Li, X. Xiao, Nat. Biotechnol. 2005, 23, 321.

[32] S. Huth, J. Lausier, S. W. Gersting, C. Rudolph, C. Plank, U. Welsch, J. Rosenecker, J. Gene Med. 2004, 6, 923.

[33] a) S. M. Moghimi, A. C. Hunter, J. C. Murray, Pharmacol. Rev. 2001, 53, 283; b) J. S. Suk, Q. Xu, N. Kim, J. Hanes, L. M. Ensign, Adv. Drug Deliv. Rev. 2016, 99, 28.

[34] a) B. Zhou, J. A. Weigel, L. Fauss, P. H. Weigel, J. Biol. Chem. 2000, 275, 37733; b) K. Y. Choi, K. H. Min, J. H. Na, K. Choi, K. Kim, J. H. Park, I. C. Kwon, S. Y. Jeong, J. Mater. Chem. 2009, 19, 4102.

[35] S.-d. Li, L.-y. Huang, Gene Ther. 1997, 4, 891.

[36] Y. He, G. Cheng, L. Xie, Y. Nie, B. He, Z. Gu, Biomaterials 2013, 34, 1235.

[37] P. W. Riddles, R. L. Blakeley, B. Zerner, Anal. Biochem. 1979, 94, 75. 


\section{The table of contents}

We developed a multi-responsive "turn-on" polyelectrolyte complex DNA/OEI-SSx/HASS-COOH (DSS) to combat multiple biological barriers in non-viral gene delivery. DSS can respond to the alterations of hyaluronidases and glutathione in tumor sites and intracellular milieu. DSS were designed to accumulate and become internalized in CD44-expressing tumor, and then to activate endosomal escape and gene release mechanisms, resulting in efficient gene transfection.

Keywords: gene delivery, nanocarriers, multi-responsive, site-specific, biological barriers

Title: Multi-responsive "turn-on" nanocarriers for efficient site-specific gene delivery in vitro and in vivo

Yiyan He ${ }^{1}$, Jie Zhou ${ }^{1}$, Shengnan $\mathrm{Ma}^{1}$, Yu Nie ${ }^{1}$, Dong Yue ${ }^{1}$, Qian Jiang ${ }^{1}$, Aisha Roshan Mohamed Wali', James Zhenggui Tang ${ }^{2}$, Zhongwei Gu ${ }^{l *}$

ToC figure

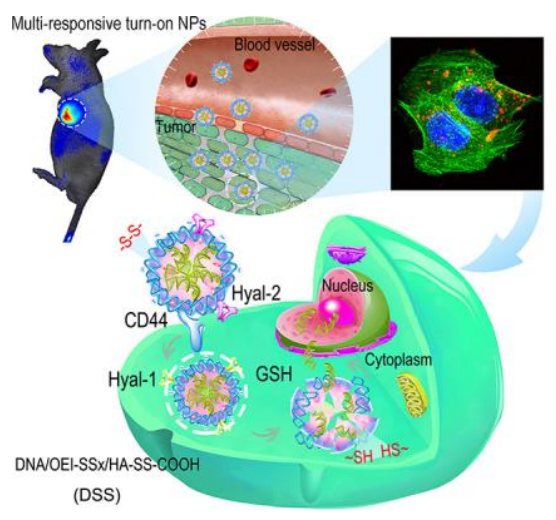


Copyright WILEY-VCH Verlag GmbH \& Co. KGaA, 69469 Weinheim, Germany, 2013.

\section{Supporting Information}

Multi-responsive "turn-on" nanocarriers for efficient site-specific gene delivery in vitro and in vivo

Yiyan He ${ }^{1}$, Jie Zhou ${ }^{1}$, Shengnan $\mathrm{Ma}^{1}, \mathrm{Yu}_{\mathrm{Ni}}{ }^{1}$, Dong Yue ${ }^{1}$, Qian Jiang ${ }^{1}$, Aisha Roshan Mohamed Wali $^{2}$, James Zhenggui Tang ${ }^{2}$, Zhongwei Gu ${ }^{1 *}$

${ }^{1}$ National Engineering Research Center for Biomaterials, Sichuan University, 29 Wangjiang Road, Chengdu 610064, P. R. China.*E-mail: zwgu@scu.edu.cn \& zwgu1006@hotmail.com (Prof. Zhongwei Gu); Fax: +86-28-85410653.

${ }^{2}$ Faculty of Science and Engineering, School of Pharmacy, University of Wolverhampton, Wulfruna Street, Wolverhampton WV1 1SB, UK

Keywords: gene delivery, nanocarriers, multi-responsive, site-specific, biological barriers 

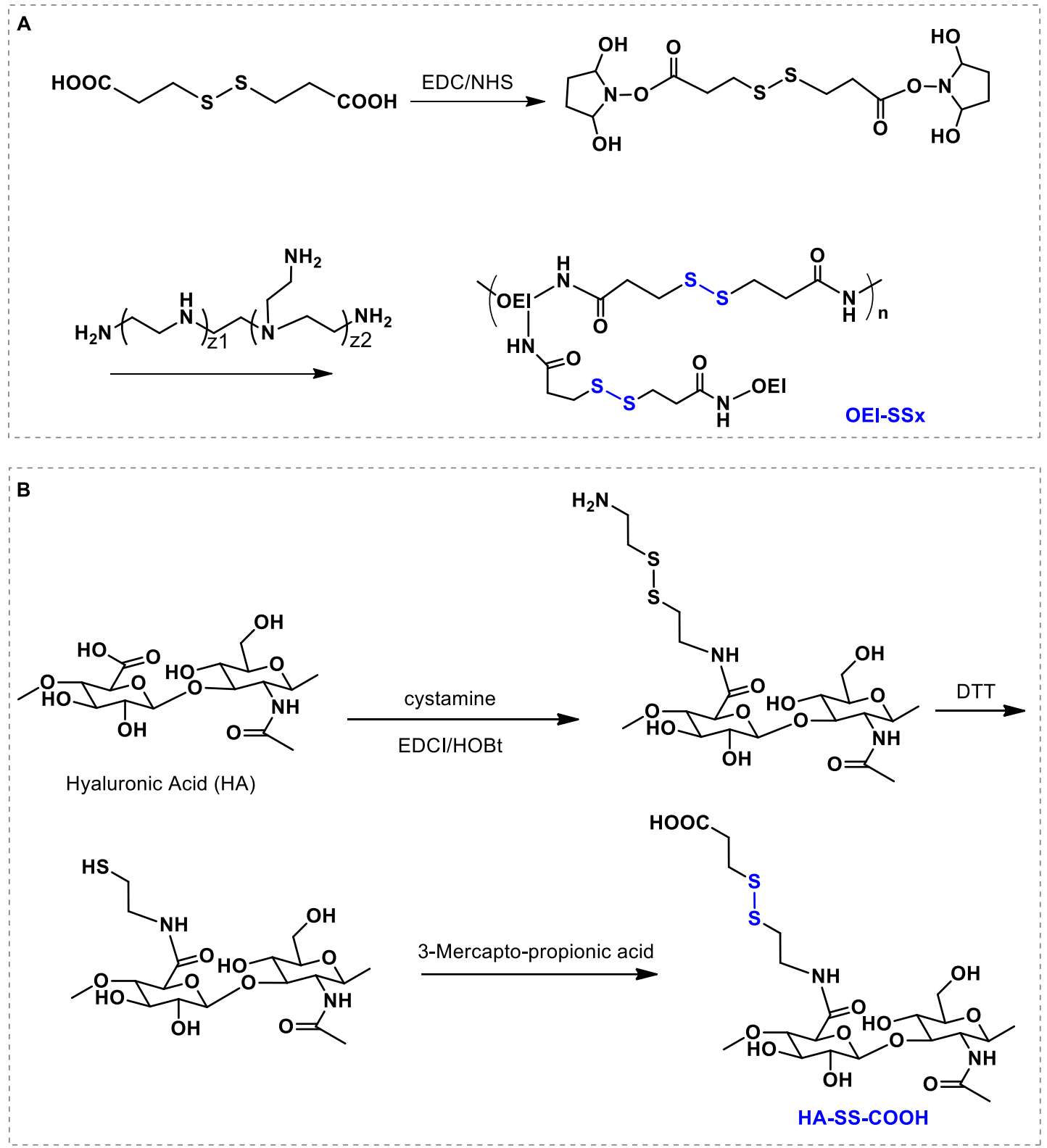

Figure S1. Schematic preparation and molecular structure of $(\mathrm{A})$ the disulfide-conjugated oligoethylenimine (OEI-SS $\left.{ }_{\mathrm{x}}\right)$ and (B) the disulfide bond modified HA (HA-SS-COOH). 

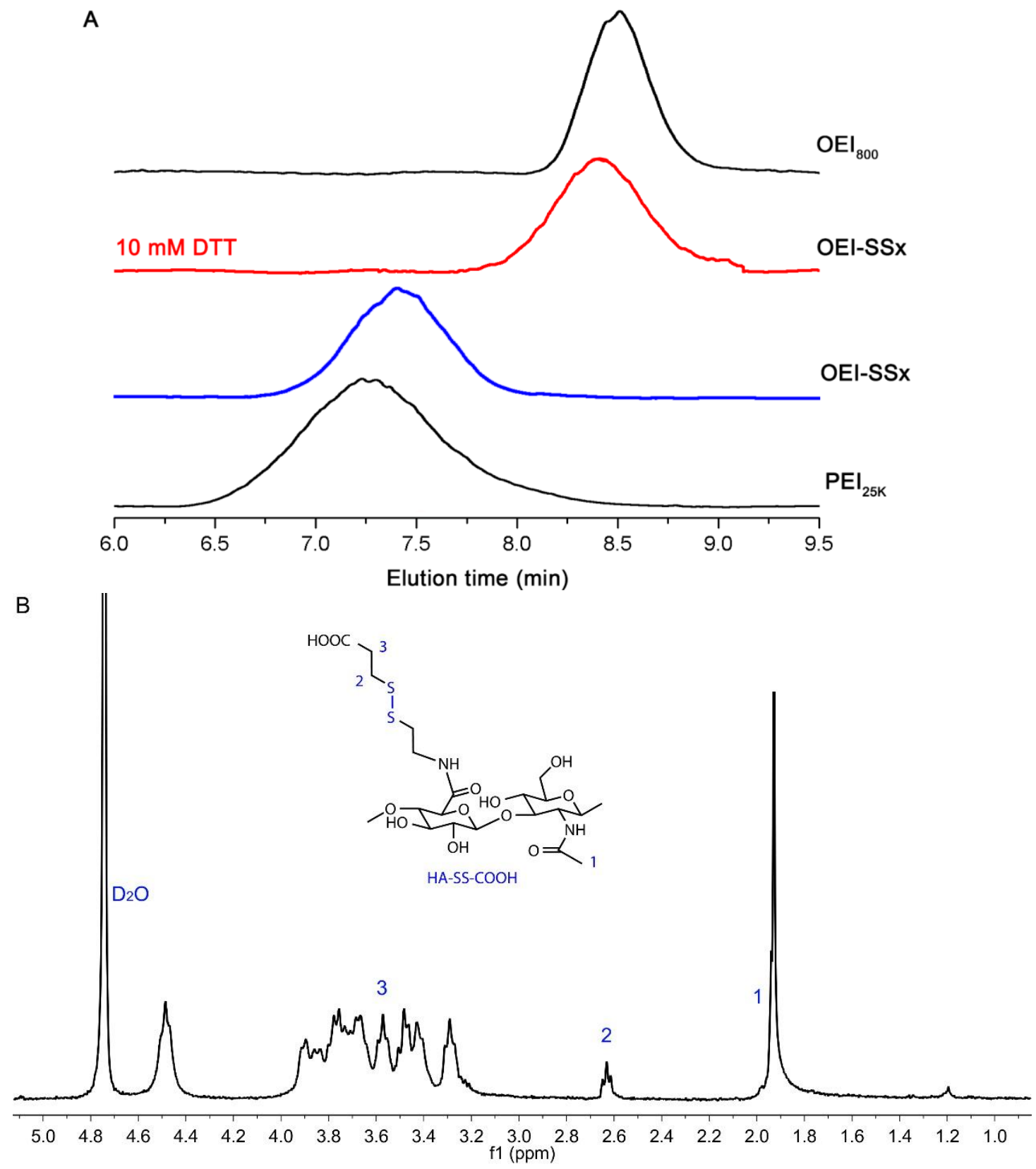

Figure S2. (A) GPC diagrams of $\mathrm{OEI}_{800 \mathrm{Da}}, \mathrm{OEI}_{-\mathrm{SS}}$ (with and without DTT treatment) and $\mathrm{PEI}_{25 \mathrm{kDa}}$. (B) ${ }^{1} \mathrm{H}-\mathrm{NMR}$ Spectrum of the disulfide bond modified HA (HA-SS-COOH) in $\mathrm{D}_{2} \mathrm{O}$. 


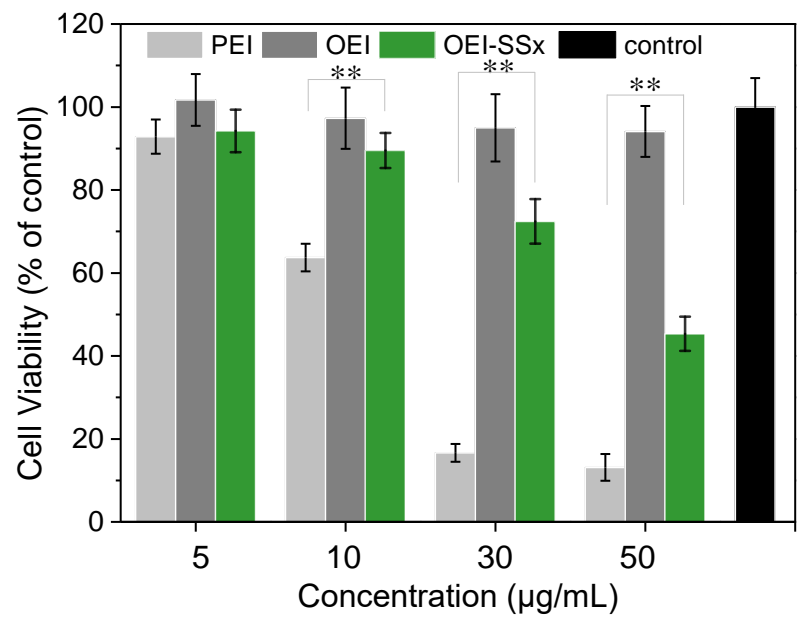

Figure S3. Concentration-dependent cytotoxicity of $\mathrm{PEI}_{25 \mathrm{kDa}}, \mathrm{OEI}_{800 \mathrm{Da}}$ and OEI-SSx on HepG 2 cells for $24 \mathrm{~h}$ of incubation ( $\mathrm{n}=6, * * p<0.05$ by one-way ANOVA, followed by Tukey's post-hoc test).
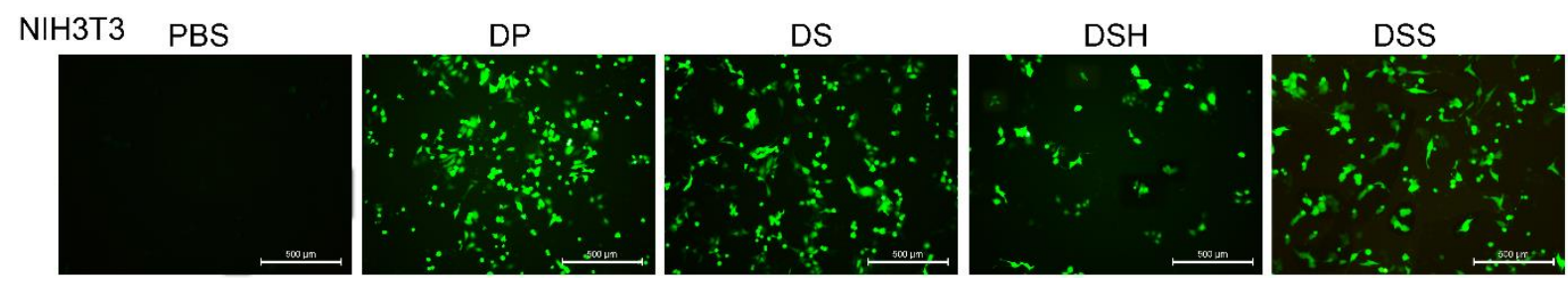

Figure S4. GFP reporter gene expression of gene carriers at their optimized weight ratios on NIH3T3 cells (scale bar $=500 \mu \mathrm{m})$. 